\title{
Circumpolar vegetation dynamics product for global change study
}

\author{
Alemu Gonsamo*, Jing M. Chen \\ Department of Geography and Planning, University of Toronto, Toronto, M5S 3G3, ON, Canada \\ * Correspondence author. E-mail: gonsamoa@geog.utoronto.ca (A. Gonsamo)
}

\begin{abstract}
Land surface phenology (LSP) and vegetation growth of the circumpolar north are changing in response to more pronounced warming in the region. We here introduce the first phenology index (PI) based vegetation dynamics product, comprising start (SOS), end (EOS), length of growing season (LOS), and growing season integrated annual normalized difference vegetation index (NDVI), specifically designed for the entire circumpolar north $\left(>45^{\circ} \mathrm{N}\right)$ using SPOT VGT data starting from 1999. PI combines the merits of NDVI and normalized difference infrared index (NDII) by taking the difference of squared greenness (from NDVI) and wetness (from NDII) to remove the soil and snow cover dynamics from key vegetation LSP cycles. The results show that the circumpolar vegetation dynamics and their spatial distributions are realistically detected. Further validation based on North American and European deciduous broadleaf, evergreen needleleaf and mixed forests, and wetland flux tower sites shows good agreements between the LSP dates from the circumpolar vegetation dynamics and ground phenology estimates from $\mathrm{CO}_{2}$ flux measurements. The validation also proves that the circumpolar vegetation dynamics product is an improvement over the operational global MODIS Combined Land Cover Dynamics (MCD12Q2) product for the circumpolar region. The results are further compared with the interannual variability of sea ice extent and leading teleconnection patterns in the region. The circumpolar averaged results show that, the growing season integrated annual NDVI is significantly increasing $\left(0.68 \% \mathrm{yr}^{-1}, p=0.006\right)$ and well correlated with the growing season sea ice extent trend
\end{abstract}


( $p=0.007)$. The circumpolar vegetation dynamics is more related to Polar/ Eurasia pattern (i.e., indicator of circumpolar vortex) than to Scandinavian Pattern (SCA) and North Atlantic Oscillation (NAO). In view of the considerable scientific and policy importance of the circumpolar region, particularly the arctic ecosystems, the presented circumpolar vegetation dynamics product will greatly contribute to study changes in plant growth, phenology, photosynthetic capacity, and associated feedbacks under climate change.

Keywords: Circumpolar, Phenology index, Sea ice, Teleconnection index, Vegetation productivity

\section{Introduction}

Land surface phenology (LSP), the study of the timing of recurring seasonal pattern of variation in vegetated land surfaces observed from synoptic sensors (de Beurs and Henebry 2004; Gonsamo et al. 2012b), has received much attention due to its role as a surrogate in detecting the impact of climate change on terrestrial ecosystems. LSP and vegetation growth of the northern hemisphere circumpolar region are changing (Bhatt et al. 2013; Jeganathan et al. 2014; Tucker et al. 2001; Xu et al. 2013; Zeng et al. 2011; Zhang et al. 2004) in response to disproportionately pronounced warming, and, by inference, its effect on natural physical and biological systems in this region (Hinzman et al. 2005; Post et al. 2009; Serreze et al. 2000; Stroeve et al. 2012). Knowing how the circumpolar vegetation ecosystems are responding to recent and persistent climate change is paramount to understanding the future state of the Earth system. The circumpolar region is experiencing pronounced warming (Polyakov et al. 2002) and the warming is expected to be enhanced in the future through the Arctic amplification process (Miller 2013). This has also been reflected in severe changes in LSP of the circumpolar region (Buitenwerf et al. 2015). The observed pronounced contemporary shifts in climate and LSP in the circumpolar region help understand changes that may come in the decades ahead on other regions of the Earth. LSP is a sensitive and valuable indicator of the dynamic responses of circumpolar vegetation ecosystems to climate 
change. LSP changes may exacerbate or moderate rates of climate change by altering energy and gas exchanges between the land surface and the atmosphere. Several adverse consequences of circumpolar LSP changes for land-surface-climate feedbacks (Bonan 2008), ecosystems (Post et al. 2009) and species with synchronized life cycles (Both et al. 2006) have already been observed. Therefore, to better understand and predict circumpolar ecosystems dynamics related to global change, it is important to reduce uncertainties in detecting vegetation growth and LSP changes.

Earth system and ecosystem process models require LSP modules to initialise photosynthetic processes in order to study the impacts of global warming on vegetated ecosystems. LSP parameterisation schemes included in Earth system and ecosystem process models, experimental warming, and contemporary climate-dependent processes such as growing degree days, underpredict plant phenological responses to global warming and do not reflect the changing climates (Arora and Boer 2005; Gonsamo et al. 2013b; Migliavacca et al. 2012; Wolkovich et al. 2012). This is because global change has altered the phenology and distribution of many land and marine plant and animal species, evidenced in coherent fingerprint of climate change impacts across natural systems (Edwards and Richardson 2004; Parmesan and Yohe 2003; Poloczanska et al. 2013; Walther 2010; Walther et al. 2002; Wolkovich et al. 2012). Therefore, observational studies are paramount to analyse climate change impacts across natural systems; in particular, terrestrial ecosystems provide a consistent picture of observed changes through retrieval of surface parameters from spatially and temporally continuous satellite observations.

In the last four decades, several LSP products derived from Advanced Very High Resolution Radiometer (AVHRR) (Justice et al. 1985), Moderate Resolution Imaging Spectroradiometer (MODIS) (Zhang et al. 2003), and Medium Resolution Imaging Spectrometer (MERIS) (Dash and Curran 2004) sensors were produced. They mostly use the normalized difference vegetation index (NDVI), but also 
enhanced vegetation index (EVI) and terrestrial chlorophyll index (MTCI), to extract start (SOS) and end of growing season (EOS) using vegetation index (VI) threshold or curve fitting algorithms (see comparison and reviews in: Atkinson et al. 2012; Fensholt and Proud 2012; Fensholt et al. 2009; Schwartz and Hanes 2010; White et al. 2009). However, the application of a single VI is difficult for circumpolar vegetation due to limitations such as contaminations by background reflectances (e.g., from soil, leaf litter, dead branches, snow, soil thaw, snow thaw, and shadows), which also have distinct seasonal dynamics often misinterpreted as vegetation seasonal cycle (e.g., Boles et al. 2004; Delbart et al. 2005; Gonsamo et al. 2013a; Jackson and Huete 1991; Jin and Eklundh 2014; Shabanov et al. 2002; Todd and Hoffer 1998). NDVI, EVI, and MTCI respond to greenness, wetness and dryness dynamics, from which LSP extraction in as predominantly snow covered areas as circumpolar region is far from trivial. These shortcomings are well documented in previous studies (Delbart et al. 2005; Delbart et al. 2006; D’Odorico et al. 2015; Gonsamo et al. 2012a; Jin and Eklundh 2014; White et al. 2009).

Studies have shown the use of shortwave infrared (SWIR) reflectance in VI construction, such as, normalized difference infrared index (NDII), to improve LSP extractions from satellite reflectance observations (Delbart et al. 2005; Delbart et al. 2006; Delbart et al. 2008). However, NDII-based methods do not work well in regions where snowmelt and greenup processes overlap, and in conditions of abrupt increase in soil moisture before greenup, typical of circumpolar ecosystems. Gonsamo et al. (2012a) developed a new VI called phenology index (PI) which combines the merits of NDVI and NDII by taking the difference of squared greenness (from NDVI) and wetness (from NDII) to remove the soil and snow cover dynamics from key vegetation LSP cycles. PI based LSP estimates performed well in previous validations at northern $\mathrm{CO}_{2}$ flux tower sites for both needleleaf and deciduous broadleaf plant forms (Gonsamo et al. 2013a; Gonsamo et al. 2012a; Gonsamo et al. 2012b). A recent site-level intercomparison study reveals that PI based LSP estimates agree with ground phenology estimates from 
$\mathrm{CO}_{2}$ flux measurements and digital camera observations better than EVI based MODIS Global Land Cover Dynamics product (MCD12Q2) and NDVI based LSP estimates at 19 temperate and boreal deciduous broadleaf forest sites (D’Odorico et al. 2015). The next logical step is to apply PI over spatially and temporally continuous satellite observations and analyse the relationship between the resulting circumpolar vegetation dynamics product and the integrated anthropogenic and natural global change indicators in the region. The longest running modern satellite sensor, Satellite Pour l'Observation de la Terre Vegetation (SPOT VGT) with all required spectral bands (i.e., red, near infrared (NIR), and SWIR) provides operational level data to apply PI for LSP mapping. We use seasonally and annually averaged sea ice extent to represent the integrated anthropogenic global change and three leading circumpolar ocean-atmosphere oscillation patterns to represent the natural internal climate variability.

In this paper, we present the first phenology index (PI) based circumpolar vegetation dynamics product, specifically designed for the entire circumpolar north $\left(>45^{\circ} \mathrm{N}\right)$ using SPOT VGT data starting from 1999. The circumpolar vegetation dynamics product comprises four layers, i.e., start (SOS), end (EOS), length of growing season (LOS), and growing season integrated annual normalized difference vegetation index (NDVI) (Table 1 and 2). As an example application for global change studies, we also present the responses of the circumpolar vegetation dynamics to long-term trend and interannual variability of dominant global change indicators in the region. Further validations are provided using citizen science phenology records and ground phenology estimates from $\mathrm{CO}_{2}$ flux measurements. 


\section{Table 1}

Summary of the circumpolar vegetation dynamics product layers.

\begin{tabular}{|c|c|c|c|c|c|}
\hline Product name & Units & Data Type & Fill Value & Valid Range & *Scale Factor \\
\hline Start of season (SOS) & $\begin{array}{l}\text { Days since } \\
\text { January } 1\end{array}$ & $\begin{array}{l}\text { 16-bit signed } \\
\text { integer }\end{array}$ & 0 & $1-3660$ & 0.1 \\
\hline End of season (SOS) & $\begin{array}{l}\text { Days since } \\
\text { January } 1\end{array}$ & $\begin{array}{l}\text { 16-bit signed } \\
\text { integer }\end{array}$ & 0 & $1-3660$ & 0.1 \\
\hline Length of season (SOS) & $\begin{array}{l}\text { Number of } \\
\text { days of year }\end{array}$ & $\begin{array}{l}\text { 16-bit signed } \\
\text { integer }\end{array}$ & 0 & $1-3660$ & 0.1 \\
\hline $\begin{array}{l}\text { Daily sum of growing season } \\
\text { integrated annual NDVI }\end{array}$ & NDVI unit & $\begin{array}{l}\text { 16-bit signed } \\
\text { integer }\end{array}$ & 0 & $1-3660$ & 0.1 \\
\hline
\end{tabular}

Table 2

Common characteristics of the circumpolar vegetation dynamics product layers.

\begin{tabular}{ll}
\hline Common characteristic & Definition \\
\hline Temporal Coverage & 1999-2013 \\
Projection & Geographic Lat/Lon \\
Datum & WGS-84 \\
Pixel sizes & $0.03571428 \times 0.03571428$ degrees \\
Number of sample & 10081 \\
Number of lines & 840 \\
Byte order & Host (intel) \\
Interleave & BSQ \\
\hline
\end{tabular}

\section{Methods}

\subsection{Study area and SPOT VGT S10 data descriptions for circumpolar vegetation dynamics product}

The study area includes the entire circumpolar north $\left(>45^{\circ} \mathrm{N}\right)$. In this work, we use the $1 \mathrm{~km}$ ten-day product (S10) from SPOT VGT Maximum Value Composite (MVC) Syntheses reflectance data (Maisongrande et al. 2004) obtained from the VITO product distribution portal (http://www.vitoeodata.be/) for 1999-2013. The S10 10-day reflectance data are corrected for molecular and aerosol scattering, water vapour, ozone and other gas absorption based on a single best MVC data for every 10 days (Holben 1986). The red $(0.61-0.68 \mu \mathrm{m})$, NIR $(0.78-0.89 \mu \mathrm{m})$ and SWIR $(1.58-1.75 \mu \mathrm{m})$ reflectances are compiled from SPOT-4 (VGT1 sensor) until January 2003 and after that from the SPOT-5 (VGT2 sensor). SPOT VGT sensors offer the advantage over MODIS of longer data records 
going back to 1998 including the SWIR spectral band. The SPOT VGT sensors also offer better sunsynchronous navigation against orbital drift and improved radiometric sensitivity advantages over the most widely used AVHRR series of sensors. Some of the SWIR detectors are declared defective due to proton shocks and detector locations and consequently the data given by those detectors are ignored, and replaced by data obtained from an interpolation from the neighbours (http://www.vgt.vito.be/pages/VegetationSystem/dataprocessing.htm). However, a small number of stripes still remain after processing.

\subsection{Rationale for vegetation index used for circumpolar vegetation dynamics product}

The red, NIR and SWIR S10 reflectances are averaged to $4 \mathrm{x} 4 \mathrm{~km}(0.03571428 \mathrm{x} 0.03571428$ degrees) in order to increase the convergence of the curve fitting algorithm with statistically sufficient data points with expected temporal pattern. The LSP algorithm described in Gonsamo et al. (2012a) is applied for the years 1999 to 2013 to extract SOS and EOS dates from PI times series. The PI is calculated from red, NIR and SWIR reflectances as follows:

$$
\mathrm{PI}=\left\{\begin{array}{l}
0, \text { if } \mathrm{NDVI} \text { or } \mathrm{NDII}<0 \\
\mathrm{NDVI}^{2}-\mathrm{NDII}^{2} \\
0, \text { if } \mathrm{PI}<0
\end{array}\right.
$$

where from SPOT VGT red $(0.61-0.68 \mu \mathrm{m})$, NIR $(0.78-0.89 \mu \mathrm{m})$ and $\operatorname{SWIR}(1.58-1.75 \mu \mathrm{m})$ reflectances, NDVI $=($ NIR-red $) /(\mathrm{NIR}+\mathrm{red})$, and NDII $=(\mathrm{NIR}-\mathrm{SWIR}) /(\mathrm{NIR}+\mathrm{SWIR}) . \mathrm{NDVI}$ is an indicator of the amount of greenness while NDII captures the amount of wetness over an observational unit such as a pixel. PI is constructed on the basis of the following rationale (Gonsamo et al. 2012a): (1) NIR reflectance is less than red reflectance for ice, snow and water resulting in NDVI $<0$ for which PI becomes 0; (2) SWIR reflectance is greater than NIR for soil and for non photosynthetic vegetation component resulting in NDII $<0$ and NDVI $>0$ for which PI becomes 0; (3) if NDII $>$ NDVI, the green vegetation or land surface is covered by snow for which PI becomes 0; (4) the use of PI instead of NDVI 
or NDII masks out the time series of permanently non vegetated landscapes for which NDVI or NDII may result in spurious time series due to moisture variations resembling vegetation LSP (Fig. 1); and (5) the product of the sum and the difference of NDVI and NDII gives a pronounced and smooth curve, removes the effect of wetness from the greenness, and avoids the local solution if we simply consider the use of NDVI once the above criteria (1,2, 3 and 4) are met, which may particularly occur in needleleaf forests due to intermittent loading and unloading of snow. Generally speaking, PI is the squared difference between greenness and wetness in the growing season.

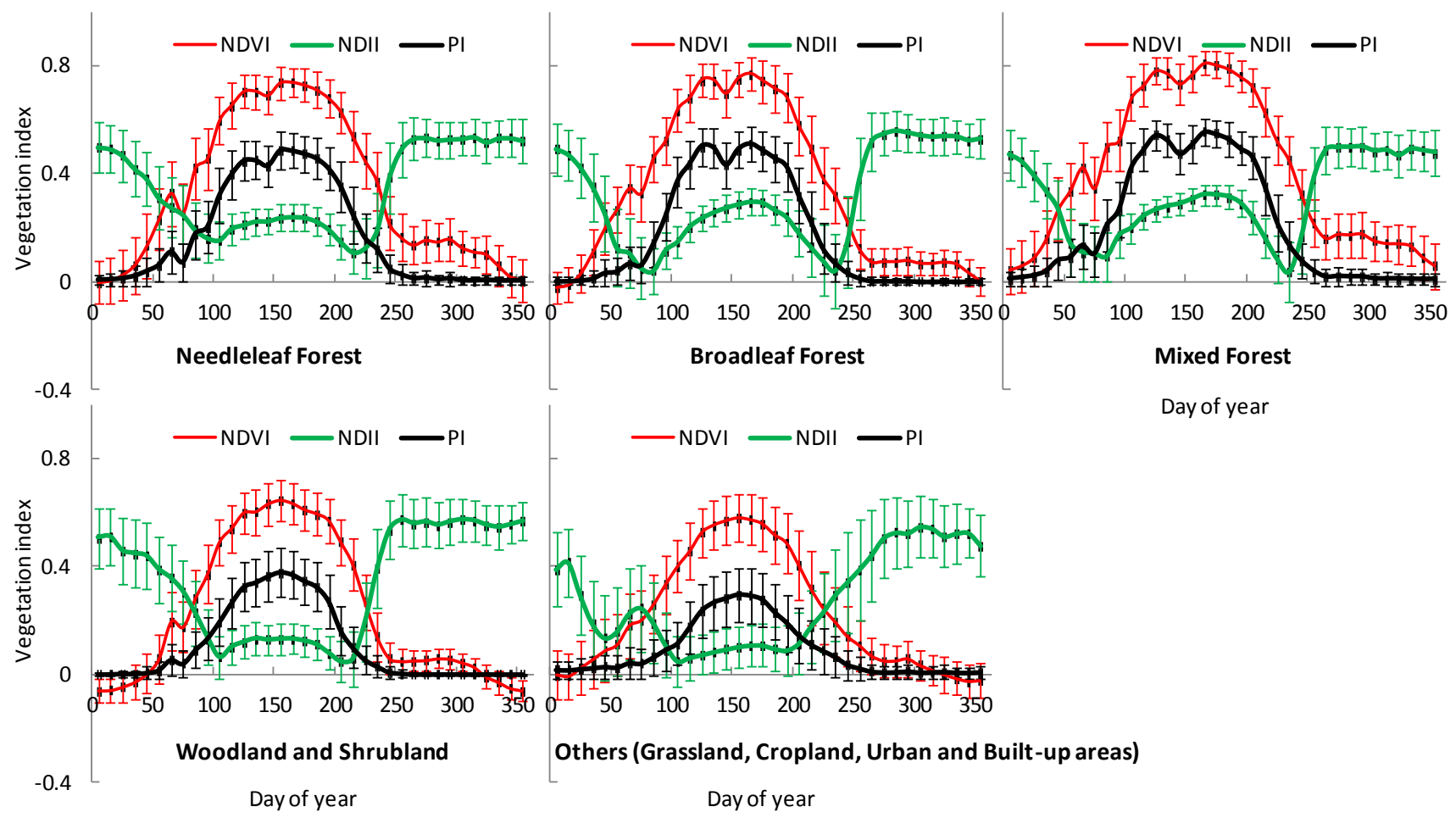

Fig. 1. Example time evolution of normalized difference vegetation index (NDVI), normalized difference infrared index (NDII) and phenology index (PI) averaged over the entire circumpolar north for the year 2013 for five biomes based on the University of Maryland Global Land Cover Classification scheme (Hansen et al. 2000). The error bars indicate 1 standard deviation of the spatial averaging. 


\subsection{Curve fitting algorithm used to extract LSP and vegetation productivity for circumpolar vegetation}

dynamics product

We used the seven parameter double logistic function to extract SOS and EOS day of year (DOY) from PI time series:

$\mathrm{PI}(\mathrm{DOY})=\alpha_{1}+\frac{\alpha_{2}}{1+e^{-\partial_{1}\left(\mathrm{DOY}-\beta_{1}\right)}}-\frac{\alpha_{3}}{1+e^{-\partial_{2}\left(\mathrm{DOY}-\beta_{2}\right)}}$

where PI(DOY) is the observed PI as a function of DOY, $\alpha_{1}$ is the background PI, $\alpha_{2}-\alpha_{1}$ is the difference between the background and the amplitude of spring and early summer plateau, and $\alpha_{3}-\alpha_{1}$ is the difference between the background and the amplitude of late summer plateau and autumn both in PI units. $\partial_{1}$ and $\partial_{2}$ are the transition in slope coefficients, and $\beta_{1}$ and $\beta_{2}$ are the midpoints in DOY of these transitions for greenup and senescence/abscission, respectively (details in: Gonsamo et al. 2013a). Both SOS and EOS were derived after fitting Eq. (2), i.e. SOS $=\beta_{1}-\left(4.562 / 2 \partial_{1}\right)$ and EOS $=\beta_{2}+$ $\left(4.562 / 2 \partial_{2}\right)($ Gonsamo et al. 2013a). The length of growing season (LOS) was obtained as the difference between EOS and SOS. The daily sum of growing season integrated annual NDVI values, representative of vegetation productivity, were obtained by summing NDVI values for those days when PI $>0$, and by multiplying the resulting sum by 10 to compensate the 10 day temporal resolution of S10 SPOT VGT data. Summary of the circumpolar vegetation dynamics product details is given in Table 1 and 2 .

2.4. Additional validations and comparisons with the leading global change and natural variability indicators in the circumpolar region

\subsubsection{Comparison with citizen science phenology records}

The previous in situ validations have shown PI based LSP estimates capture phenology estimates from $\mathrm{CO}_{2}$ flux measurements and digital camera observations better than EVI based MODIS MCD12Q2 product and NDVI based LSP estimates at several temperate and boreal needleleaf and deciduous 
broadleaf forest sites ( D’Odorico et al. 2015; Gonsamo et al. 2013a; Gonsamo et al. 2012a; Gonsamo et al. 2012b). We have carried out further validation in the current work using three sets of the northern most citizen science records. (1) Pan European Phenology network (PEP725) (PEP725 2015): we use observations of Birch (Betula Pendula) leaf unfolding and autumn leaf colouring events obtained from the PEP725 database for entire Finland for which both leaf unfolding and colouring dates are available for 1999-2005. We use Birch data among several available records partly due to Birch being the most common deciduous broadleaf tree species in northern Europe for which the highest amount of data (n110) records is available in PEP725 database. (2) PlantWatch Canada Citizen Science networks (Gonsamo et al. 2013c): we use Larch (Larix laricina) leafing out $(\mathrm{n}=9)$ and Bearberry (Arctostaphylos uva-ursi) first bloom $(\mathrm{n}=10)$ records from Dawson forest and garden $\left(64.06^{\circ} \mathrm{N}, 139.43^{\circ} \mathrm{W}\right.$, Yukon Territory, Canada). This record is the longest running and northern most data record in PlantWatch Canada Citizen Science networks with concomitant meteorology measurements. (3) U.S.A. Long-Term Ecological Research (LTER) Bonanza Creek station (Anderson et al. 2014): we use greenup records $(\mathrm{n}=15)$ defined as the date when leaf buds in Birch and Aspen open just enough to produce a faint but distinct green lush in the forest canopy (Anderson et al. 2014). The records are from Chena Ridge plot in Bonanza Creek station $\left(64.811^{\circ} \mathrm{N}, 147.98^{\circ} \mathrm{W}\right.$, Alaska, U.S.A.). This record is the longest running and northern most data record in LTER with concomitant meteorology measurements.

In addition to citizen science phenology records from U.S.A. LTER and PlantWatch Canada Citizen Science networks, we have also extracted growing degree days (GDD) calculated from daily minimum (Tmin) and maximum (Tmax) in situ air temperature with $0^{\circ} \mathrm{C}$ base temperature (Tbase) (i.e., GDD $=((\operatorname{Tmax}+\mathrm{Tmin}) / 2)-$ Tbase $)$. The spring GDD (accumulated from January to May months) were used to compare with SOS estimated in this study and spring phenology records from citizen science 
data. Annually accumulated GDD were compared with the growing season integrated annual NDVI from this study.

\subsubsection{Comparison of circumpolar vegetation dynamics with MODIS and GPP phenology estimates}

The first logical step for any new land surface product from satellite observation is to analyse its performance relative to exiting operation products. Therefore, we compare LSP dates from the circumpolar vegetation dynamics and the MODIS Terra+Aqua Combined Land Cover Dynamics (MCD12Q2) products against gross primary productivity (GPP) based LSP estimates from North American and European $\mathrm{CO}_{2}$ flux tower sites (Table 3). The GPP based LSP dates were extracted for 145 site-years used in previous studies (D’Odorico et al. 2015; Gonsamo et al. 2012a) and additional new sites. The flux tower sites comprise deciduous broadleaf forest (DBF), evergreen needleleaf forest (ENF), mixed forest (MIX), and wetland (WL) to represent typical northern landscapes.

\section{Table 3}

List of FLUXNET $\mathrm{CO}_{2}$ eddy covariance tower sites used in this analysis.

\begin{tabular}{|c|c|c|c|c|c|}
\hline Site & Biomes & Latitude & Longitude & Years & Site references \\
\hline $\mathrm{CA}-\mathrm{OA}$ & DBF & 53.63 & -106.20 & 2001-2012 & Black et al. (1996) \\
\hline DE-HAI & $\mathrm{DBF}$ & 51.08 & 10.45 & $2000-2012$ & Knohl et al. (2003) \\
\hline DK-SOR & $\mathrm{DBF}$ & 55.49 & 11.64 & $2000-2012$ & Pilegaard et al. (2011) \\
\hline FR-FON & $\mathrm{DBF}$ & 48.48 & 2.78 & $2005-2008$ & Le Maire et al. (2005) \\
\hline FR-HES & $\mathrm{DBF}$ & 48.67 & 7.07 & $2000-2010$ & Granier et al. (2000) \\
\hline UK-HAM & DBF & 51.15 & -0.86 & $2000-2012$ & Wilkinson et al. (2012) \\
\hline US-UMB & $\mathrm{DBF}$ & 45.56 & -84.71 & $2000-2010$ & Gough et al. (2013) \\
\hline US-WCR & $\mathrm{DBF}$ & 45.81 & -90.08 & $2000-2006$ & Cook et al. (2004) \\
\hline CA-EOBS & ENF & 49.69 & -74.34 & 2004-2009 & Bergeron et al. (2007) \\
\hline CA-NOBS & ENF & 55.88 & -98.48 & $2001-2008$ & Dunn et al. (2007) \\
\hline CA-SOBS & ENF & 53.99 & -105.12 & 2001-2009 & Bergeron et al. (2007) \\
\hline BE-VIE & MIX & 50.31 & 6.00 & $2000-2012$ & Aubinet et al. (2001) \\
\hline CH-LAE & MIX & 47.48 & 8.37 & 2005-2012 & Ahrends et al. (2008) \\
\hline CA-MER & WL & 45.41 & -75.52 & $2000-2010$ & Lafleur et al. (2003) \\
\hline US-LOS & WL & 46.08 & -89.98 & 2001-2006 & Sulman et al. (2009) \\
\hline
\end{tabular}


The SOS, EOS and LOS dates from daily GPP $\left(\mathrm{g} \mathrm{C} \mathrm{m}^{-2} \mathrm{~d}^{-1}\right)$ time-series were derived using Eq. (2), the same way they were derived from PI (Gonsamo et al. 2012a; Gonsamo et al. 2013a). The daily total GPP, calculated as the sum of observed daytime net ecosystem $\mathrm{CO}_{2}$ exchange (NEE) and modeled ecosystem respiration inferred from night-time NEE, was obtained as a gap-filled level-4 data product from the Ameriflux and the Euroflux Databases. Details of partitioning algorithm, gap filling and $\mathrm{CO}_{2}$ storage calculations are given in Reichstein et al. (2005), Moffat et al. (2007), and Papale et al. (2006), respectively. Ninety percent of stable (day time) $\mathrm{CO}_{2}$ flux, used for daily GPP, usually comes from the area less than $500 \mathrm{~m}$ of the flux tower site (Chen et al. 2009). The comparability of the LSP dates derived from the EC flux footprint and the $4 \times 4 \mathrm{~km}$ remote sensing pixel depends on and increases with site homogeneity. Therefore, we have excluded agricultural crop, grassland, and northern non-forest flux sites with shorter towers and corresponding smaller footprints from analysis. Although WL sites included in the current intercomparison also have small footprint, we assume that they represent the surrounding dominant plant function type at each location.

The MCD12Q2 product is provided at a yearly time step since 2001 and is currently the only operational global product that includes LSP variables. The MCD12Q2 product is derived from 8-day EVI composite values calculated from MODIS Nadir Bidirectional Reflectance Distribution Function Adjusted Reflectance (NBAR) at $463.3 \times 463.3 \mathrm{~m}$ pixel size. The MCD12Q2 LSP dates are retrieved based on the rate of change in curvature of the fitted two sigmoid functions (Zhang et al. 2003). Among several MCD12Q2 product layers, we use Onset Greenness Increase layer as SOS and Onset Greenness Minimum layer as EOS, and their difference as LOS. To make comparable validation, we average the MCD12Q2 LSP estimates centered at a tower site pixel over 9x9 pixels equalling approximately $4 \times 4 \mathrm{~km}$ nominal spatial resolution, the same as the circumpolar vegetation dynamics pixel size. 
Some site-years do not have successful LSP retrievals from both circumpolar vegetation dynamics and the MCD12Q2 products. These site-years were excluded from comparison. For the MCD12Q2 product, we only average pixels which have successful retrievals within each 9x9 pixel grid. Although the high latitude $\mathrm{CO}_{2}$ flux tower sites with clear seasonality such as deciduous plant forms are preferred to comparatively analyse both the circumpolar vegetation dynamics and MCD12Q2 products against independent data, the mid latitudes sites provide added challenge for rigorous evaluation. In boreal ENFs, in early spring when solar irradiance is near the seasonal maximum, photosynthesis occurs prior to snowmelt if canopy temperatures are thawed. Furthermore, the intermittent loading and unloading of intercepted snow on the ENF canopy provides the needed challenge for which the circumpolar vegetation dynamics product is designed. However, at far north latitudes, there is a large shoulder between the last snow in spring and greenup, and between senescence and the first snow in autumn because leaf developments are highly controlled by day length (e.g., Fig. 5 in Gonsamo et al 2012a). The mid latitude compared to the high latitude sites are generally characterised by overlap of snowmelt and green-up and conditions of abrupt increase in soil moisture before greenup. These phenomena present opportunities to rigorously evaluate the circumpolar vegetation dynamics product and compare its performance against an independent validation dataset in relation to the performance of the existing operational global MCD12Q2 product.

\subsubsection{Comparison of circumpolar vegetation dynamics with sea ice extent}

Monthly means calculated from daily sea ice extent (SIE) from the Special Sensor Microwave/Imager onboard the Defense Meteorological Satellite Program were obtained from the National Snow and Ice Data Center (NSIDC) (Fetterer et al. 2009). SIE is the total area covered by at least 15 percent of ice. The SIE data is spatially averaged time series from the circumpolar northern hemisphere region $\left(>31^{\circ} \mathrm{N}\right)$. We use seasonal and growing season annual SIE time series values in this study. 


\subsubsection{Comparison of circumpolar vegetation dynamics with leading teleconnection indices in the region}

The natural ocean-atmosphere oscillations, expressed using teleconnection indices relating oceanic and atmospheric climate anomalies at large distances, modulate the location and strength of storm tracks and fluxes of heat, moisture, and momentum (Quadrelli and Wallace 2004; Wallace and Gutzler 1981). Many teleconnection indices have been shown to affect global and regional vegetation productivity (Gonsamo and Chen 2015; Gonsamo et al. 2015; Iizumi et al. 2014; Woodward et al. 2008). We restricted the teleconnection indices to those that dominate the interannual variability of climatic oscillations in phase and amplitude with circumpolar implications accounting for the most spatial variance of the observed standardized anomaly (Barnston and Livezey 1987; Quadrelli and Wallace 2004; Wallace and Gutzler 1981). The three selected teleconnection indices (Barnston and Livezey 1987; Wallace and Gutzler 1981): North Atlantic Oscillation (NAO), Scandinavian Pattern (SCA), and Polar/ Eurasia Pattern (POL) are obtained from the National Oceanic and Atmospheric Administration $\begin{array}{llll}\text { (NOAA) National } & \text { Weather } & \text { Service }\end{array}$ (http://www.cpc.ncep.noaa.gov/data/teledoc/telecontents.shtml). We use the winter, defined here as December of the preceding year and January, February and March of the NDVI year, teleconnection indices for each year because most of the leading teleconnection indices are only active in winter, their winter phase is indicative of the ensuing summer weather pattern, and they provide predictive power for summer time crop yield forecasting in northern hemisphere ahead of time. We then removed trends from the resulting winter teleconnection index by detrending the time series for the 1999-2013 base period.

\subsection{Analysis}

The spatial distributions of LSP and vegetation productivity averaged for the entire period (i.e., 19992013) over the entire circumpolar north are presented with equal frequency 10 quantile categories for visual evaluation. The pixel-by- pixel temporal trend statistics presented in Fig. 6 are calculated using 
the Theil-Sen method for pixels which have successful retrievals for all 15 years. All spatially averaged circumpolar vegetation dynamics product layers (i.e., SOS, EOS, LOS and the growing season integrated annual NDVI) trend statistics against calendar years are calculated using a simple least squares linear regression. The product layers are also compared to each other after spatially averaging for the entire study area partially to diminish the effects of stochastic noise and random retrieval errors therefore the contributions of the spring and autumn phenology dates to growing season length and growing season integrated annual NDVI can be analysed with confidence. To minimize the risk of detecting spurious correlations, we present interannual co-variability analyses from the detrended data to examine relationships between circumpolar vegetation dynamics product, and seas ice extent dynamics and leading teleconnection indices in the region. To investigate if the correlations are worthy of interpretation, we also analyse trend relationships between circumpolar vegetation dynamics product, and leading teleconnection indices in the region and seas ice extent dynamics after spatial averaging to diminish the effects of stochastic noise and random retrieval errors. SOS and the growing season integrated annual NDVI are compared to citizen science phenology records and growing degree days (GDD). To avoid misregistration of in situ and SPOT-VGT pixel, it is preferable to compare the in situ records to the averaged circumpolar vegetation dynamics product values on pixels of the same vegetation type around phenology recording station as phenology is driven by climate, and thus does not display strong short-scale gradient (Delbart et al. 2005). Therefore, for PlantWatch Canada Citizen Science and U.S.A LTER Bonanza Creek phenology records, we use 20x20km averaged circumpolar vegetation dynamics product around the recording and meteorology stations. However, for PEP725 records over entire Finland, each ground observation record is compared to a single satellite $4 \times 4 \mathrm{~km}$ pixel, representing the integrated response across landscapes with diverse species and phenological behavior within each pixel. Finally, the circumpolar vegetation dynamics and the MODIS MCD12Q2 
LSP estimates were compared against 145 site-years GPP based LSP estimates over DBF, ENF, MIX, and WL plant functional types.

\section{Results and discussion}

\subsection{Evaluation of the circumpolar vegetation dynamics product using citizen science phenology records}

Statistically significant relationships were obtained between PI based SOS and ground leaf unfolding observations from entire Finland (Fig. 2). However, EOS and LOS did not show significant relationships with autumn leaf colouring and the number of days between autumn leaf coloring and leaf unfolding, respectively. The two different sources of LSP dates do not observe exactly the same phenological events and, thus, modest correlations, particularly for spring activity was expected as also proven by the PEP725 synthesis study (Rodriguez-Galiano et al. 2015).
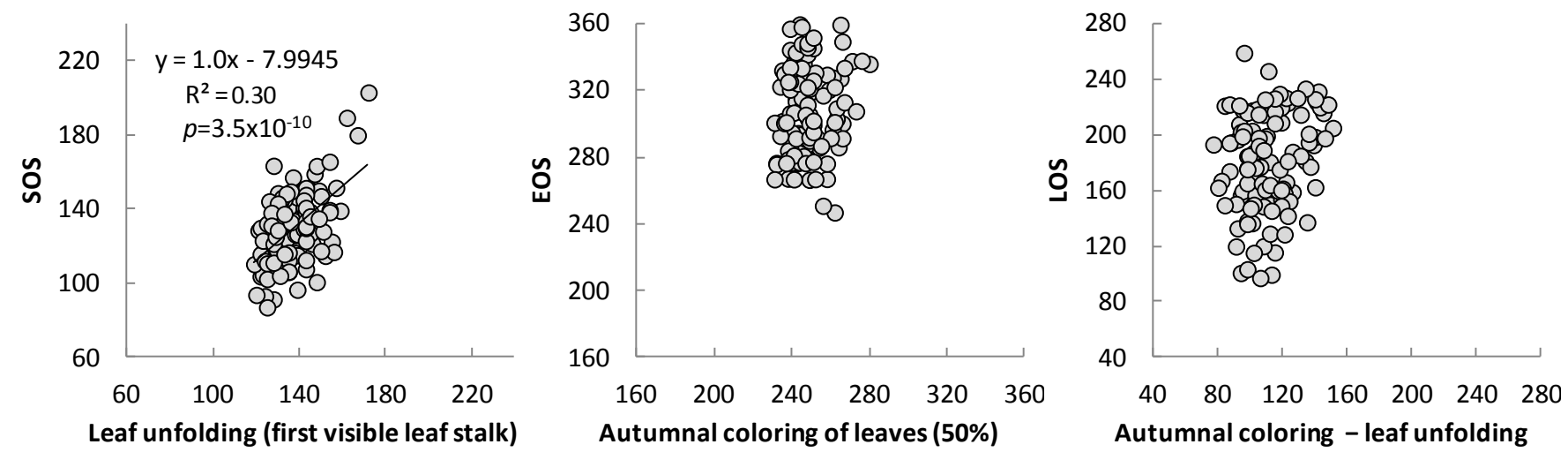

Fig. 2. Comparisons between satellite estimated LSP and ground phenology observations of Birch (Betula Pendula) which were obtained from Pan European Phenology network (PEP725) (PEP725 2015) for entire Finland for which both leaf unfolding and colouring dates are available for 1999-2005 $(\mathrm{n}=110)$. Each satellite $4 \times 4 \mathrm{~km}$ pixel is compared with a single ground observation record. 
Further validation is shown in Fig. 3 between station based spring phenology records and meteorology observations, and SOS and growing season integrated annual NDVI. Although there were strong correlations $(p<0.05)$ between SOS and spring GDD, and growing season integrated annual NDVI and annual GDD at both sites, SOS does not correlate well with the in situ leafing and blooming days. Both in situ and PI based spring phenology dates correlate significantly $(p<0.05)$ with spring GDD at both sites, indicating that both, remote sensing and in situ phenology dates, are responding to the same climate variables but differently. This indicates both in situ and remote sensing LSP and vegetation productivity variables could differ regardless of how accurately they are retrieved.

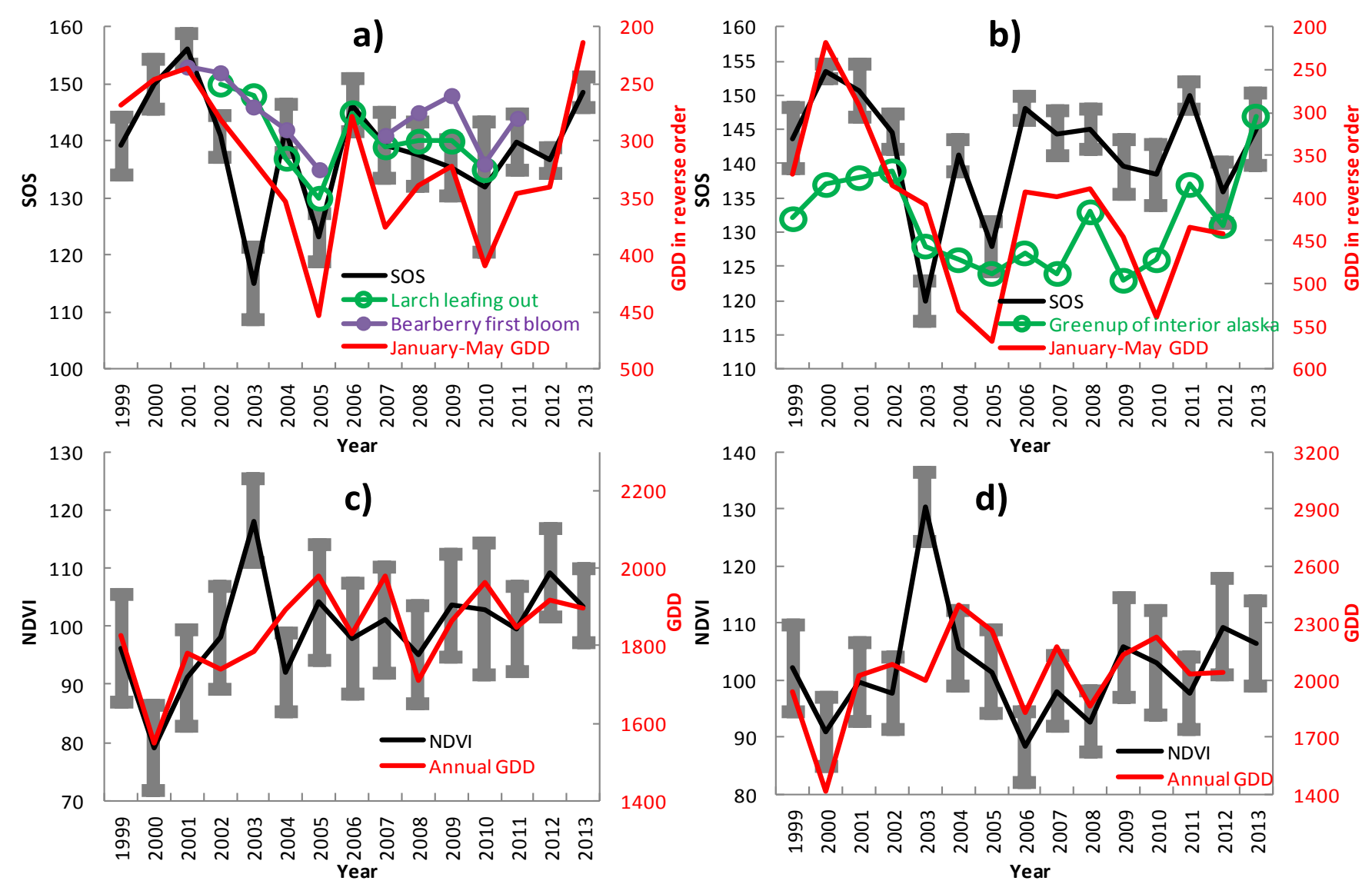

Fig. 3. Comparisons between circumpolar vegetation dynamics product, and ground phenology and meteorology observations. From Canada Citizen Science networks phenology records: a) SOS day of 
year (DOY) relationship with Larch leafing out $(\mathrm{n}=9, R=0.13, p=0.739)$, Bearberry first bloom day ( $\mathrm{n}=$ $10, R=0.51, p=0.136)$ and January-May growing degree day (GDD) $(R=-0.66, p=0.006)$; and $\mathrm{c})$ relationship between growing season integrated annual NDVI and annual GDD ( $R=0.57, p=0.026)$. From U.S.A LTER Bonanza Creek phenology records: b) SOS relationship with greenup DOY ( $n=15$, $R=0.49, p=0.063)$ and January-May GDD $(R=-0.58, p=0.024)$; and d) relationship between growing season integrated annual NDVI and annual GDD $(R=0.57, p=0.026)$. For all sites, the SOS and annual NDVI values are extracted over 20x20 km areas around phenology recording sites, and both the average and standard deviation (error bars) values are presented.

While a variety of field programs for monitoring phenology have been initiated (e.g., Beaubien and Hamann 2011; Richardson et al. 2009; Richardson et al. 2007; Rodriguez-Galiano et al. 2015), these programs mostly involving digital repeat photography and citizen science records provide data that are typically species-specific, collected at scales that are not compatible with coarse resolution remote sensing observations. Each observation program measure different phenological stages and has different sources of uncertainties (e.g., Balzarolo et al. 2016; Dickinson et al. 2010; D’Odorico et al. 2015; Gonsamo and D'Odorico 2014; Liang et al. 2011; Liu et al. 2016; Rodriguez-Galiano et al. 2015), which make comparison in absolute terms challenging. Each pixel in the $4 \times 4 \mathrm{~km}$ circumpolar vegetation dynamics products presented here reflects the integrated response across landscapes with diverse species and phenological behavior. While there have only been limited attempts to "directly" validate remote sensing LSP with ground observations, further rigorous statistical approaches should be developed to fully understand and validate large-scale phenology in terrestrial vegetation.

\subsection{Evaluation of the circumpolar vegetation dynamics and MODIS phenology products using GPP-} based phenology estimates 
Results of the comparative analysis of LSP dates based on the circumpolar vegetation dynamics and the MCD12Q2 products against the GPP based estimates are illustrated in Fig. 4. The summary statistics averaged for all plant functional types (PFTs) are also given in each panel. All coefficients of correlation given in Fig. 4 are statistically significant for SOS, EOS and LOS estimates from the circumpolar vegetation dynamics product but uncertainties expressed in root mean square error (RMSE) are high. In terms of LSP estimation uncertainties, bias for the circumpolar vegetation dynamics ranges from +4 to +17 for SOS,+2 to +13 for EOS and -9 to +3 days for LOS for different PFTs compared to GPP based estimates. Overall, the LSP dates from the circumpolar vegetation dynamics follow the 1:1 line with that of GPP based estimates (Fig. 4).
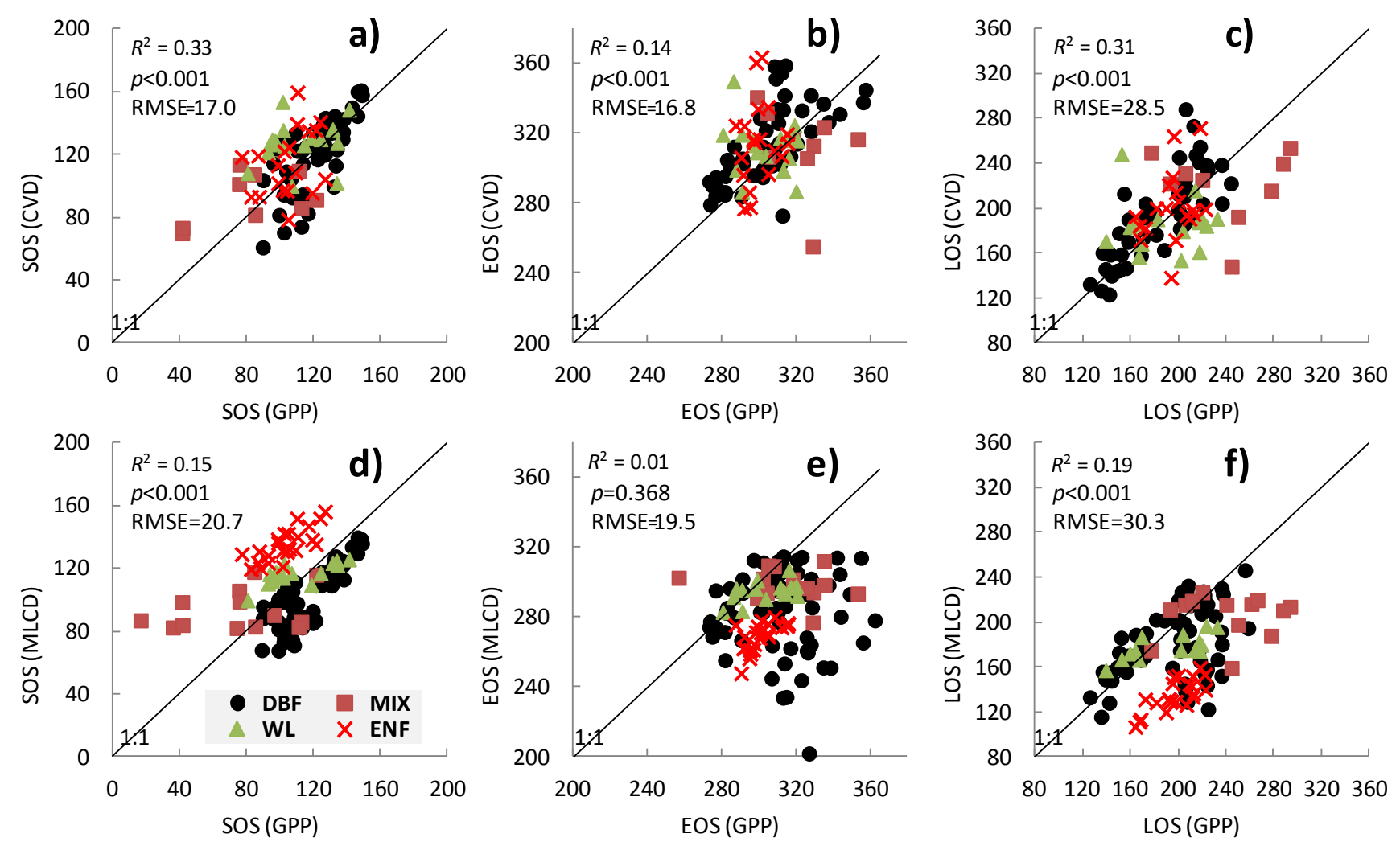

Fig. 4. Evaluation of PI-based circumpolar vegetation dynamics (CVD) and MODIS-based Land Cover Dynamics (MLCD, MCD12Q2) against land surface phenology estimates from in situ gross primary 
productivity (GPP) measurements. Site descriptions are given in Table 3. DBF $=$ deciduous broadleaf forest, $\mathrm{ENF}=$ evergreen needleleaf forest, $\mathrm{MIX}=$ mixed forest, and $\mathrm{WL}=$ wetland. Both CVD and MLCD land surface phenology estimates are from $4 \times 4 \mathrm{~km}$ grid for each site.

The EOS estimated from MCD12Q2 does not show any relationship with the GPP based estimates (Fig. 4e). The MCD12Q2 SOS also shows strong PFT depended bias (Fig. 4d). MCD12Q2 bias ranges from -14 to +31 for SOS, -33 to -9 for EOS and -14 to -64 days for LOS for different PFTs relative to GPP based estimates. Given that the MCD12Q2 $4 \mathrm{~km}$ grid is averaged around each tower site while the circumpolar vegetation dynamics estimates are obtained from $4 \mathrm{~km}$ grid overlapping the tower site with maximum geo-location misalignment of $2.8 \mathrm{~km}\left(\sqrt{\left(\frac{4}{2}\right)^{2}+\left(\frac{4}{2}\right)^{2}}\right.$, we expected better performance from the MCD12Q2 product. Furthermore, the MCD12Q2 product uses snow and ice flag from the MODIS NBAR product together with the MOD11A2 land surface temperature to filter out data points associated with snow-covered surfaces from the input EVI time series. Nevertheless, LSP dates from the MOD12Q2 product differ greatly from GPP based estimates. Previous site-level validation also shows that PI based LSP estimates agree with ground LSP estimates from GPP and digital camera observations better than the MCD12Q2 product (D'Odorico et al. 2015). Given that our product is intrinsically designed to suit the circumpolar region, its improved performance on this region compared to the global MCD12Q2 product is expected.

\subsection{Maps and trends of the circumpolar vegetation dynamics}

Fig. 5 presents the spatial distributions of the mean SOS, EOS and LOS, and growing season integrated annual NDVI during the period 1999-2013 at 4x4 km spatial resolution for the entire circumpolar north $\left(>45^{\circ} \mathrm{N}\right)$. Visual inspection of this figure shows that the phenological transition dates and the spatial 
distribution of NDVI are realistically detected. Our results show that more than $10 \%$ of the entire circumpolar land area start of growing season commences after the last week of June while $10 \%$ of the area has growing season length less than two months.

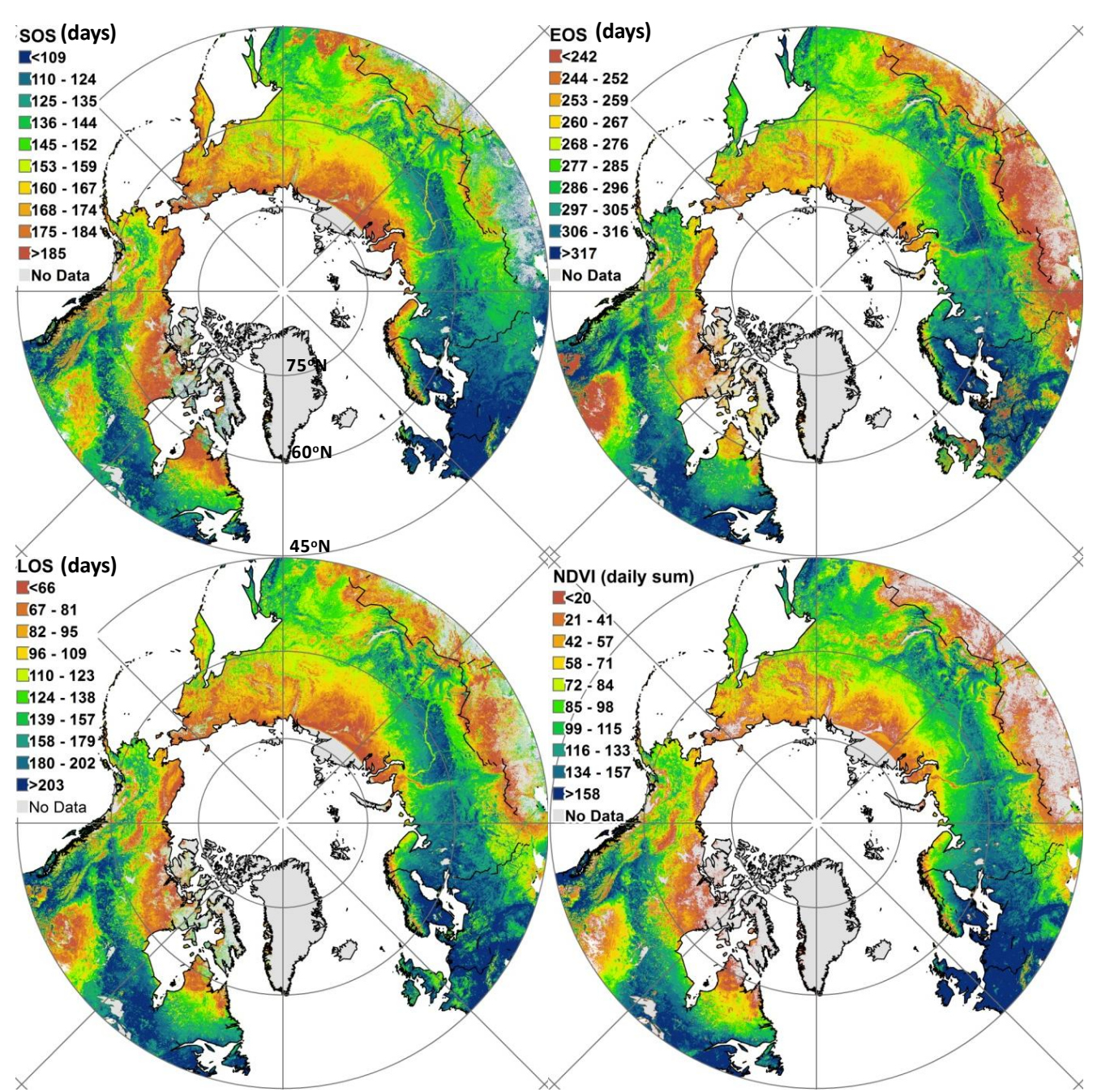

Fig. 5. Spatial distributions of the mean SOS, EOS, LOS and the growing season integrated annual NDVI of the circumpolar north $\left(>45^{\circ} \mathrm{N}\right)$ during the period $1999-2013$ at $4 \times 4 \mathrm{~km}$ spatial resolution. All categories are mapped in 10 equal quantile classes, meaning each category of the legend contains $10 \%$ of the entire circumpolar north valid land pixels. The colour ramp for EOS is switched for visual clarity.

Previous studies have used NDVI (e.g., DeFries and Townshend 1994) and phenology (e.g., Yan et al., 2015) at global and regional scales, respectively for land cover classification. Our results show 
that forested ecosystems generally show earlier SOS, later EOS, longer LOS and higher growing season integrated annual NDVI values regardless of their latitudinal position relative to the non-forested ecosystems (Fig. 5). All categories in Fig. 5 are mapped in 10 equal quantile classes, meaning each category of the legend contains $10 \%$ of the entire circumpolar north valid land area mean SOS, EOS and LOS, and growing season integrated annual NDVI. In most cases, the quantile classes represent fairly homogeneous plant functional types (PFT). LSP classes that have little variability in relation to growing season integrated annual NDVI or vice versa suggest ecological stability and physiognomic continuity across the circumpolar landscapes mainly due to the common environmental growth limiting factors (i.e., temperature and radiation (Gonsamo et al. 2016a; Nemani et al. 2003)). However, areas in south eastern China, Mongolian Plateau and Kazakhstan show distinct SOS compared to EOS, LOS and growing season integrated annual NDVI and south-western Mediterranean vegetation of Europe also shows distinct EOS compared to SOS, LOS and growing season integrated annual NDVI (Fig. 5). These two regions are co-limited by temperature and precipitation (Gonsamo et al. 2016a; Nemani et al. 2003). These results show that LSP and NDVI values may not be indicative of any particular vegetation community but are rather a simple representation of a phyto-geographic region.

Fig. 6 presents the spatial distributions of the linear trends of SOS, EOS, LOS and growing season integrated annual NDVI during the period 1999-2013. To provide a meaningful statistics, only significant trends at $95 \%$ confidence level from a two tailed Student's t-test calculated using a Theil-Sen method are provided. The most significant trend observations include the advancing SOS, and increasing LOS and growing season integrated annual NDVI of tundra and northern taiga of western Eurasian (Fig. 6). The areas with significant LSP shifts are mainly due to changes in SOS than EOS. These areas coincide with areas which have the highest relationship of SOS and NDVI against spring and summer temperatures, respectively, and areas with the highest increase in spring and summer 
temperature in the last three decades (Barichivich et al. 2014; Zeng et al. 2011). More importantly, higher temperatures during the vegetation growing season and spring can cause greater peak greenness and earlier SOS, respectively. Overall, there is more increase in growing season integrated annual NDVI values than changes in LSP dates indicating enhanced growth enhancement is happening during the growing seasons regardless of the length of growing season. Areas where the growing season integrated annual NDVI is declining during the study period are related to changes in disturbance rather than climatic factors. For example, in Canada, areas with heightened mountain pine beetle infestation in western (Kurz et al. 2008) and increased forest fires in central boreal (Jiang and Zhuang 2011; Ju and Masek 2016) regions show declining growing season integrated annual NDVI (Fig. 6). Ju and Masek (2016) found significant greening of boreal forest in Quebec; our study confirms their finding and also indicates that greening was extensive throughout eastern Canada.

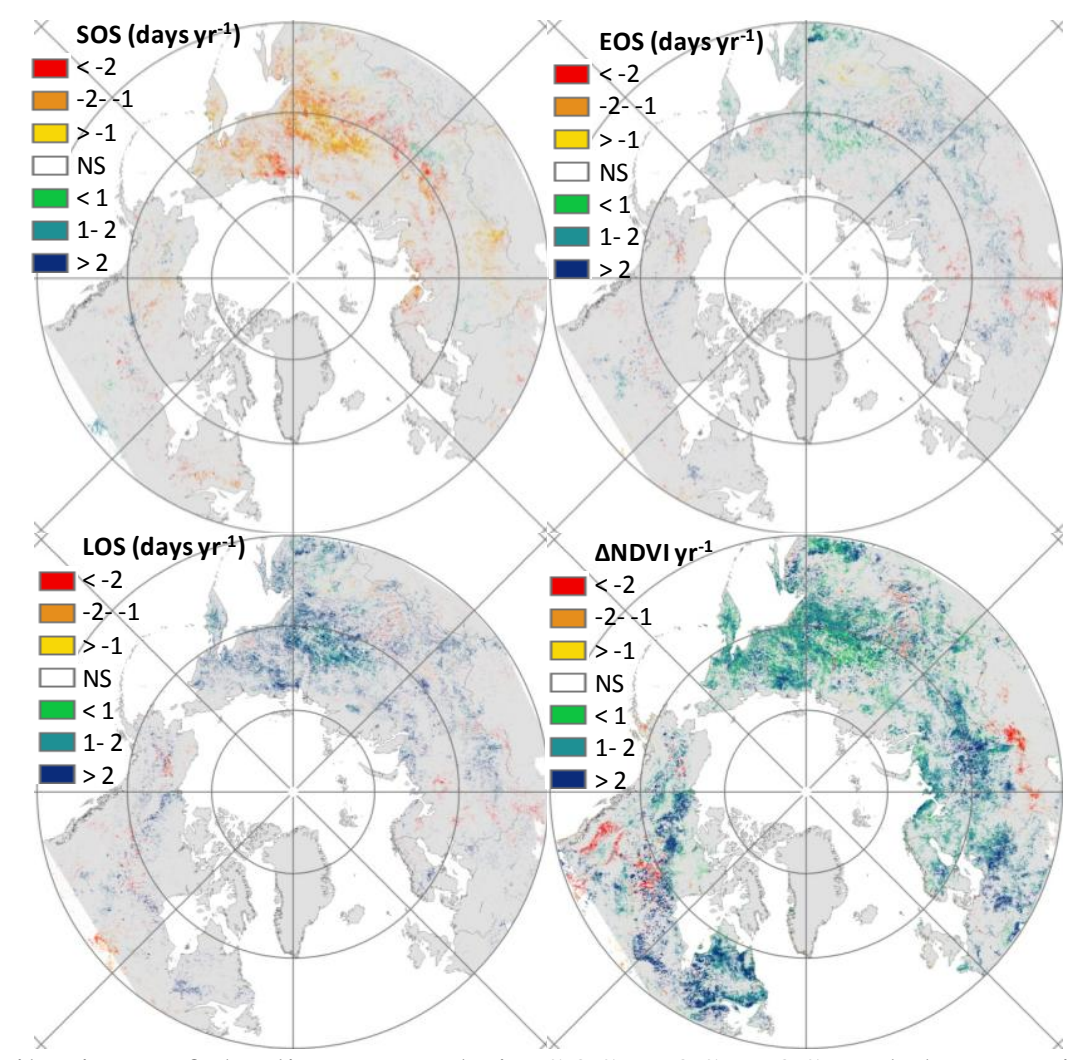

Fig. 6. Spatial distributions of the linear trends in SOS, EOS, LOS and the growing season integrated annual NDVI of the circumpolar north $\left(>45^{\circ} \mathrm{N}\right)$ during the period 1999-2013 at $4 \times 4 \mathrm{~km}$ spatial 
resolution. Linear trends are calculated using a Theil-Sen method for pixels which have successful retrievals for all 15 years. NS is not significant trend at $p=0.05$ (two tailed Student's t-test).

Fig 7 shows the relationships among spatially averaged mean annual SOS, EOS, LOS and growing season integrated annual NDVI of the entire circumpolar north $\left(>45^{\circ} \mathrm{N}\right)$ during the period 1999-2013. There are strong relationships among the area averaged circumpolar vegetation dynamics product anomalies except that of between SOS and EOS. Both SOS and EOS contribute to the anomalies of LOS and growing season integrated annual NDVI. EOS contribution has often been overlooked but recent findings are indicating that the vegetation activity in autumn is equally important for the length of growing season and overall productivity variabilities (Garonna et al. 2014; Wu et al. 2016).
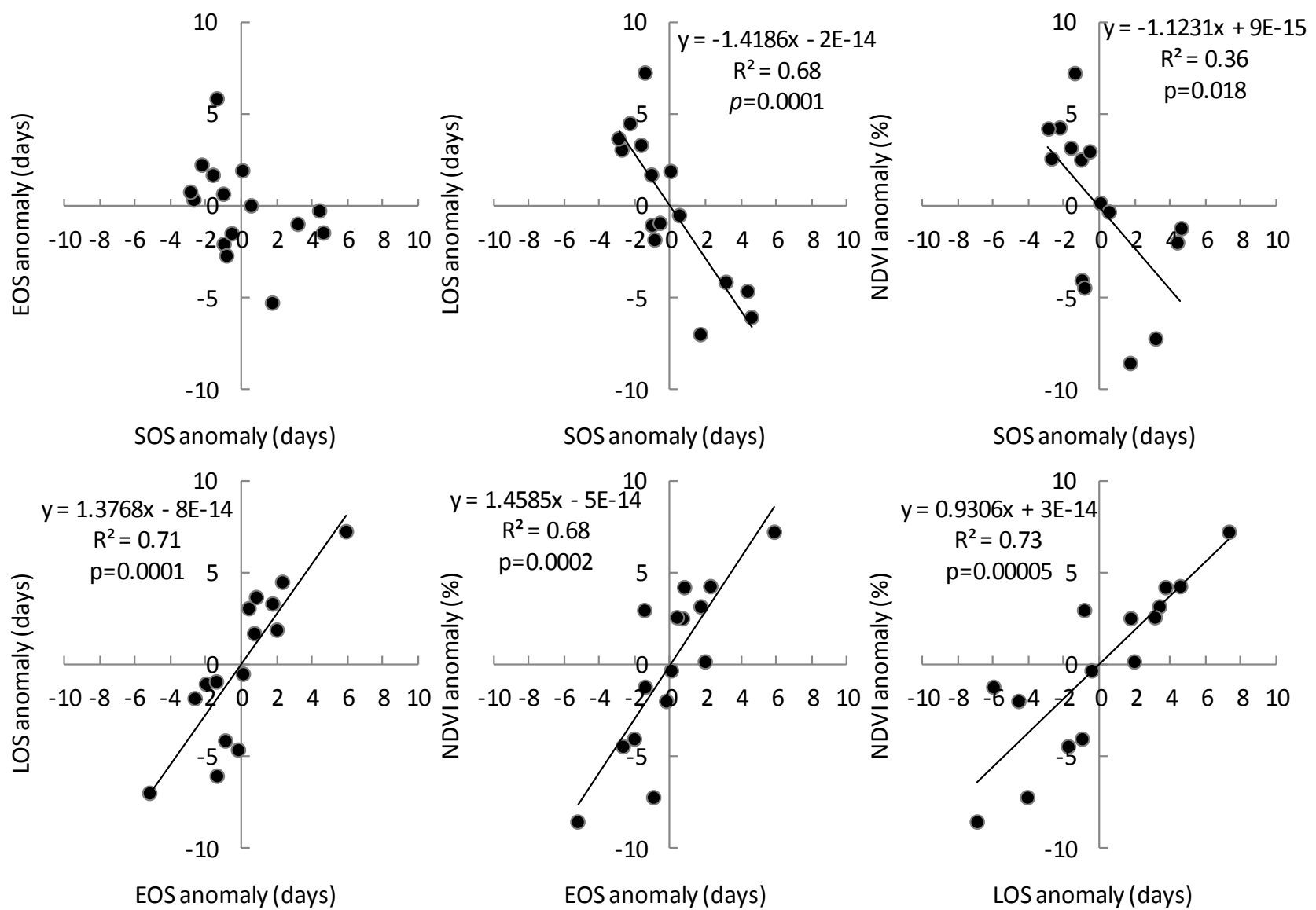
Fig. 7. Relationships among spatially averaged mean annual SOS, EOS, LOS and growing season integrated annual NDVI of the entire circumpolar north $\left(>45^{\circ} \mathrm{N}\right)$ during the period 1999-2013.

\subsection{Comparison of the circumpolar vegetation dynamics product with sea ice extent and teleconnection} indices

To provide regional perspective, we compared the circumpolar vegetation dynamics product with sea ice extent (SIE) and leading teleconnection indices which show the accumulated impacts of changes in climate variables (i.e., temperature, precipitation and radiation) on vegetation dynamics. Relationships among spring, summer and autumn SIE and SOS, EOS, LOS and the growing season integrated annual NDVI of the circumpolar north $\left(>45^{\circ} \mathrm{N}\right)$ during the period $1999-2013$ at $4 \times 4 \mathrm{~km}$ spatial resolution are given in Fig. 8. Recent rapid SIE decline is linked to several ecosystem shifts including phenology of marine animals (Post et al. 2013; Post et al. 2009). However, only rarely linked to interannual changes in vegetation productivity and phenology with few exception of trend analysis (e.g., Bhatt et al. 2013; Bhatt et al. 2010; Parmentier et al. 2013). Trend analysis over a relatively short observation record length in circumpolar ecosystems which are characterised by multiple high frequency to multidecadal time-scale internal climate variabilities (Venegas and Mysak 2000) may not yield mechanistically meaningful patterns. An expected relationship is that between mostly temperature limited northern vegetation dynamics and SIE - generally higher temperature leads to lower SIE and enhanced vegetation productivity. There is also rapid feedback from SIE such as cooling effect that sea ice has on adjacent landmasses through higher albedo and coastal landmass warming during summer sea ice decline. Other factors such as glacial history, winter temperatures, snow cover, precipitation, soil moisture, and landuse history also play important roles on circumpolar vegetation dynamics (Bhatt et al. 2013). Most of these factors are changing in the same direction in response to global changes. Therefore, we remove the trends from both SIE data and the circumpolar vegetation dynamics product to partially isolate the 
effects of other factors. There are several patch-scale local interannual co-variabilities between SIE and the circumpolar vegetation dynamics product (Fig. 8). The summer and autumn SIE affect the SOS and growing season integrated annual NDVI at the same geographic regions, meaning they all are responding to the same forcing variables. The relationships are in the expected direction, lower SIE is related to earlier SOS and higher NDVI (Fig. 8). The physical explanation is that the warming over the circumpolar region leads to SIE decline, earlier spring onset and higher summer time vegetation productivity for temperature limited regions. However, albeit we used averaged SIE time series, the satellite data quality at higher latitudes and predominantly lower solar zenith angle acquisitions may hamper the regional scale SIE and vegetation dynamics analysis. 


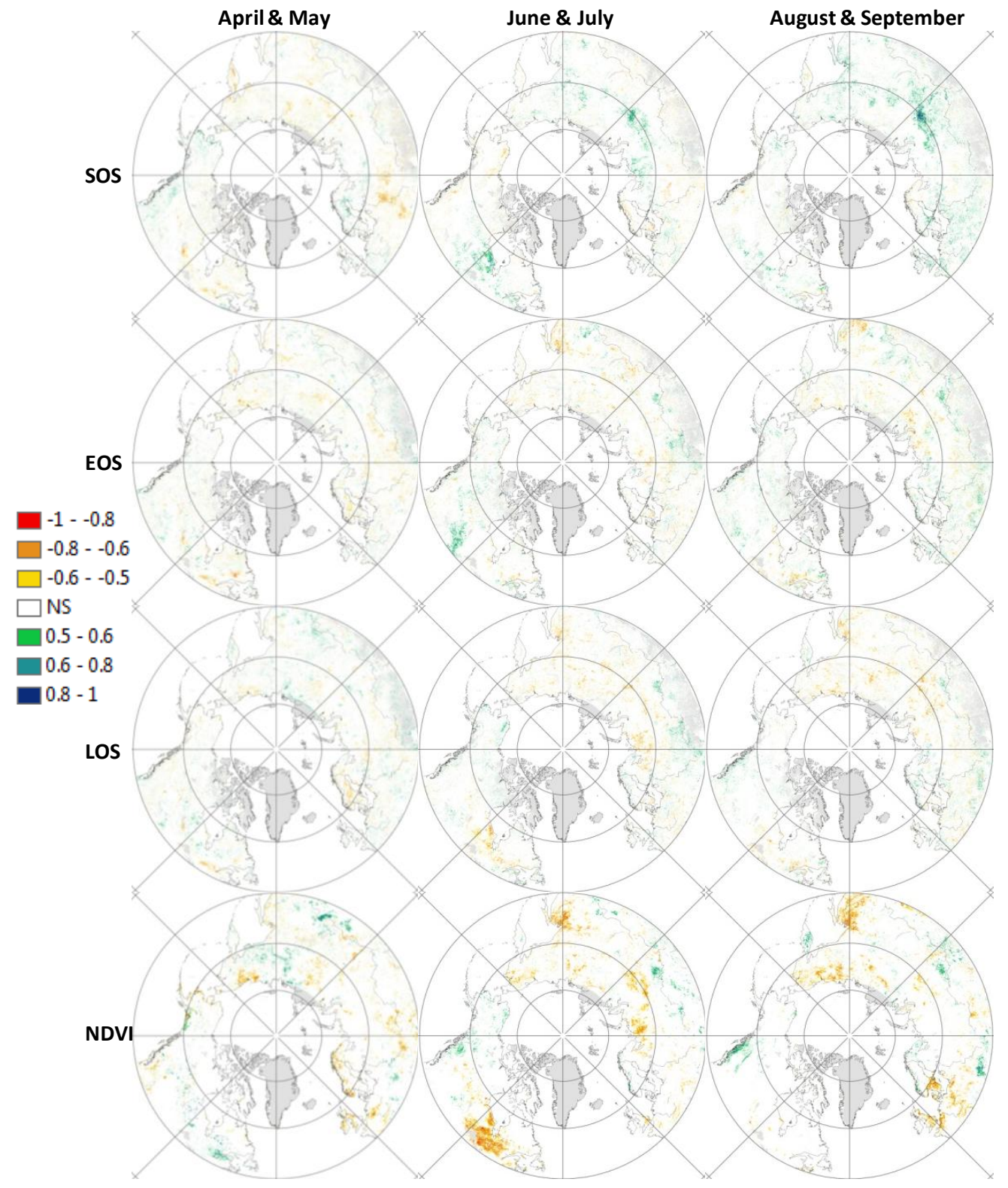

Fig. 8. Relationships among spring, summer and autumn sea ice extent and SOS, EOS, LOS and the growing season integrated annual NDVI of the circumpolar north $\left(>45^{\circ} \mathrm{N}\right)$ during the period 19992013 at $4 \times 4 \mathrm{~km}$ spatial resolution. All datasets are detrended. All colour shaded values are significant at 95\% confidence level from a two tailed Student's t-test. 


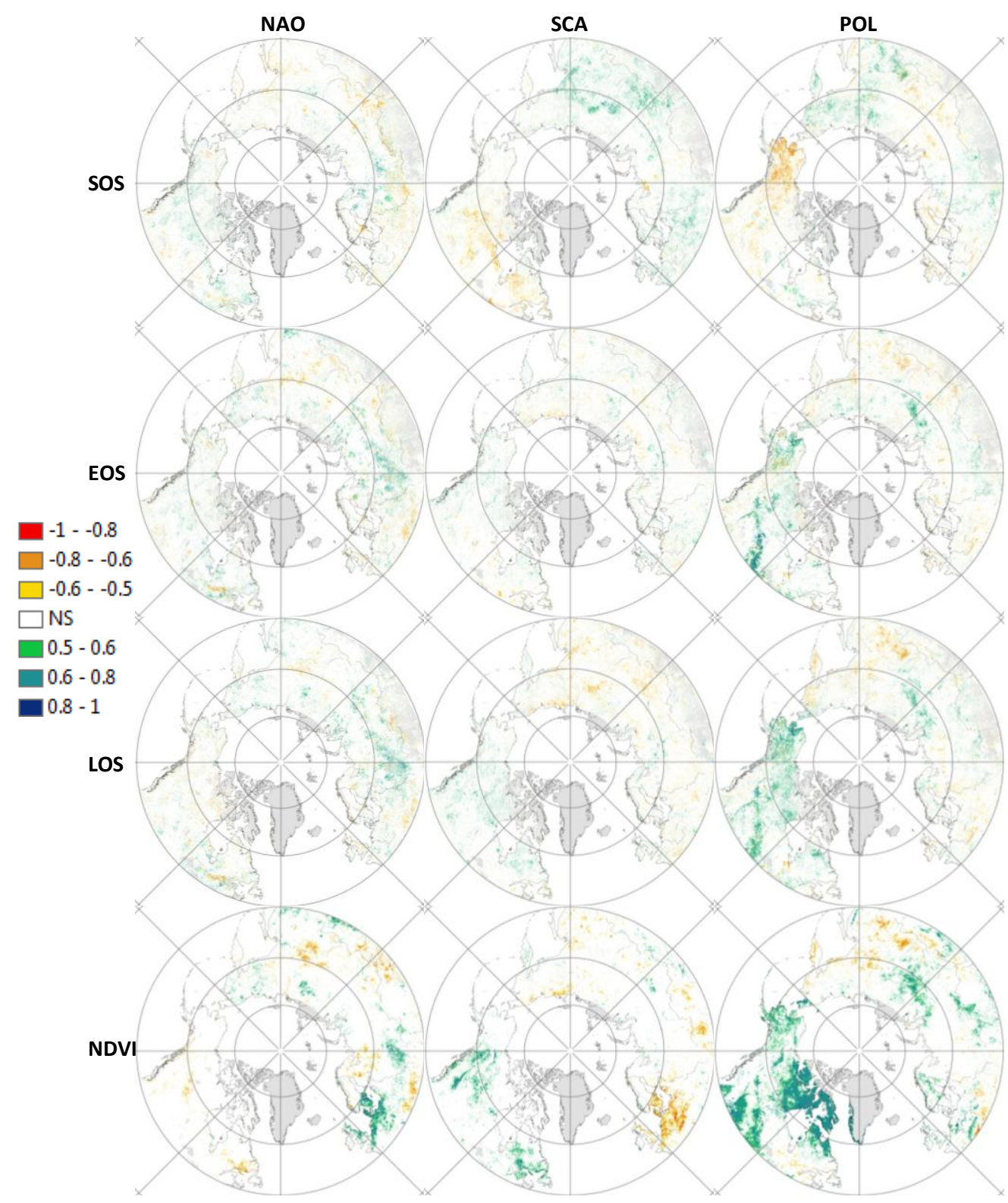

Fig. 9. Impacts of the three leading circumpolar teleconnection patterns on SOS, EOS, LOS and the growing season integrated annual NDVI of the circumpolar north $\left(>45^{\circ} \mathrm{N}\right)$ during the period 19992013 at 4x4 km spatial resolution. The Scandinavian Pattern (SCA), Polar/ Eurasia Pattern (POL) and North Atlantic Oscillation (NAO) teleconnection anomalies are calculated as a mean value of December of the preceding year and January, February and March of the LSP and NDVI year. All datasets are detrended. All colour shaded values are significant at 95\% confidence level from a two tailed Student's t-test. 
The winter time Scandinavian Pattern (SCA), Polar/ Eurasia Pattern (POL) and North Atlantic Oscillation (NAO) teleconnection anomalies are well known to affect the circumpolar climate and vegetation dynamics (Claud et al. 2007; de Beurs and Henebry 2008; Gonsamo and Chen 2015; MaciasFauria et al. 2012; Wibig 1999). NAO has strong negative relation with SCA (not presented here for the sake of brevity), affecting much of Canada and Eurasia, with SCA dominant in Midwestern Europe as a result they will have opposing impact on circumpolar vegetation dynamics in the same geographic region (Gonsamo et al. 2016a; Gonsamo et al. 2016b). POL has similarity to the Arctic Oscillation, with positive phase reflecting an enhanced circumpolar vortex, features below average heights in the polar region and the negative phase reflecting a weaker circumpolar vortex, features above average heights in polar region. NOA (SCA) has negative (positive) correlations with eastern Canada and positive (negative) correlations with central Europe growing season integrated annual NDVI (Fig. 9). The physical explanation is that steeper positive NAO phase leads to westerly wind to pick up heat and carry it across central Europe and Asia, and therefore associated with warmer Europe and Asia winter temperatures and colder and drier winters in Canada. These asymmetric trends decrease the Canadian vegetation productivity due to low temperature, and result in the opposite trend in Europe and Asia. The positive phase of POL is well correlated to increase in LOS and growing season integrated annual NDVI, delayed EOS and advanced SOS in non-forest ecosystems of circumpolar north particularly the Canadian vegetation (Fig. 9). The positive phase of POL is related to stronger circumpolar vortex which blocks the cold air spill over the mid latitudes resulting in warmer winters and springs and consequently advanced SOS and enhanced vegetation productivity. The impacts of the three teleconnection indices on LSP and vegetation productivity presented here agree well with previous findings (Aasa et al. 2004; Chmielewski and Rotzer 2002; de Beurs and Henebry 2008; Gonsamo et al. 2016a; Gonsamo et al. 
2016b; Gonsamo and Chen 2015) although we found POL having wider impacts than NAO and SCA in this study.

The results of circumpolar vegetation dynamics relationships with SIE and teleconnection indices appear to demonstrate a fairly low proportion of significant pixels due to very small degree of freedom (Figs. 8 and 9). Nevertheless, we argue that these results are important because the significant pixels show strong spatial clustering, as opposed to the expected spatially random pattern if statistics were spurious. However, results from the entire correlation analysis (not presented here) show fairly uniform spatial distribution. In order to further analyse the regional scale relevance of all environment factors and to increase the sample size for trend analysis, we present the circumpolar averaged trend relationship between each of the vegetation dynamics variable and the leading explanatory factor from Figs, 8 and 9 in Fig. 10. Over all, SOS is advancing at 0.23 days $\mathrm{yr}^{-1}$ rate and the growing season is increasing at 0.41 days $\mathrm{yr}^{-1}$ between 1999 and 2013 averaged for the entire study area and they both are positively related to the summer SIE dynamics (Fig. 10). EOS is delaying at 0.17 days $\mathrm{rr}^{-1}$ rate and positively related to POL pattern (Fig. 10). The growing season integrated annual NDVI shows statistically significant trend $(p=0.006)$, increasing $0.68 \% \mathrm{yr}^{-1}$ largely following the growing season SIE decline. During the study period, the SIE and POL patterns show growth favoring trends therefore SOS is advancing, EOS is delaying, LOS is getting longer and the overall circumpolar vegetation productivity is increasing. The implication is that with disproportionately accelerating warming of the polar region; the negative phase of POL will be prevalent in the future resulting in less sea ice extent and enhanced high latitude vegetation productivity due to adjacent landmass warming. At the same time, increased cold air spill over the mid latitudes due to weak circumpolar vortex decreases the mid latitude vegetation productivity. These opposing relationships, together with externally forced global changes and other 
altered climate variability patterns may result in contrasting effects on vegetation productivity both latitudinally and longitudinally.

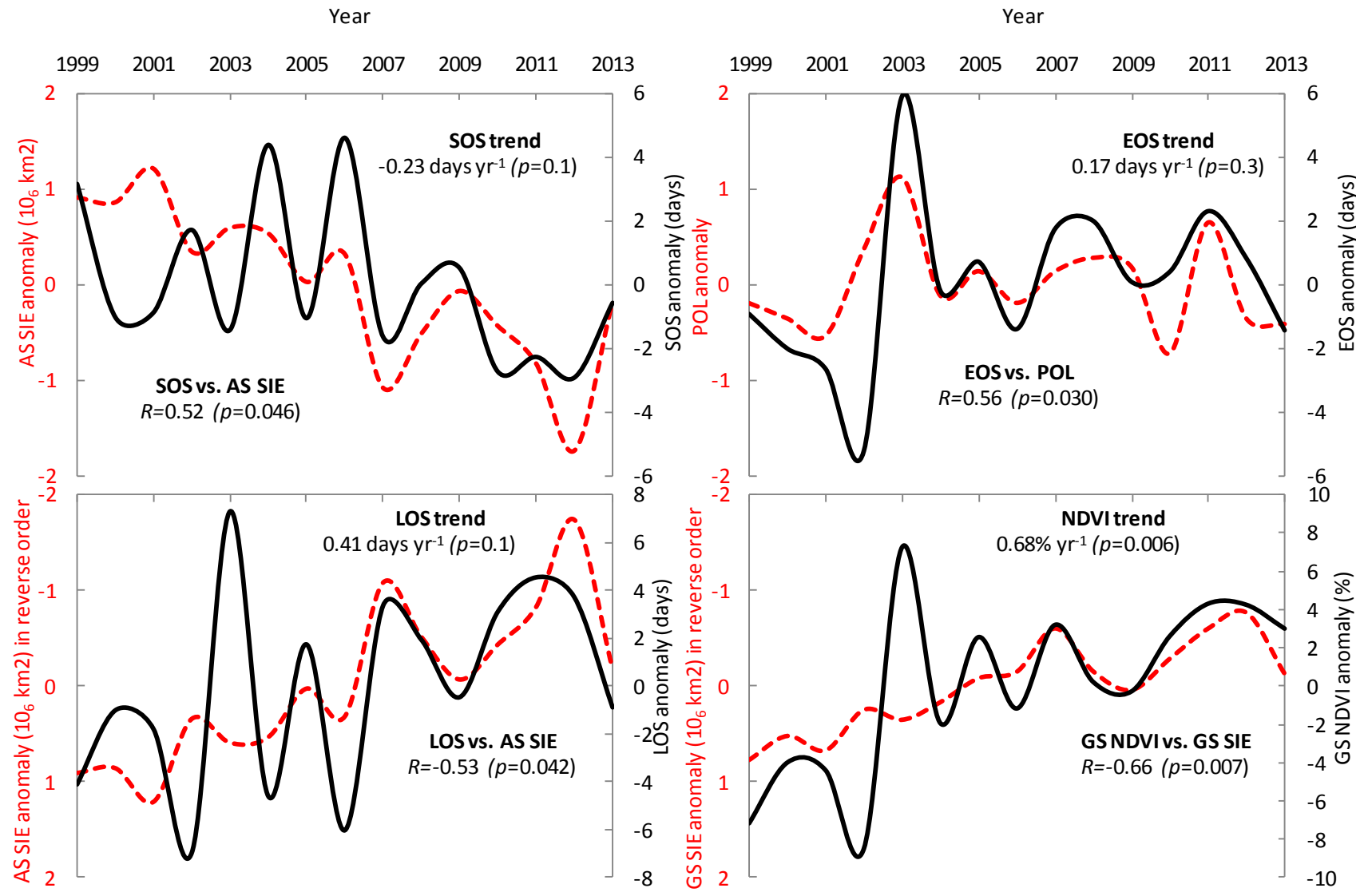

Fig. 10. Long-term trend relationships between the mean anomalies of SOS, EOS, LOS and the growing season integrated annual NDVI of the circumpolar north $\left(>45^{\circ} \mathrm{N}\right)$, and the most explaining variables from Fig. 8 and 9 interannual variability relationships. AS SIE = August and September sea ice extent, POL = Polar/ Eurasia Pattern, and GS = growing season. Growing season sea ice extent (GS SIE) is calculated as average of April to September values.

\section{Conclusions}

The first circumpolar vegetation dynamics product, comprising: 1) start of growing season (SOS), 2) end of growing season (EOS), 3) length of growing season (LOS), and 4) growing season integrated annual 
normalized difference vegetation index (NDVI) layers, specifically designed for the entire circumpolar north $\left(>45^{\circ} \mathrm{N}\right)$ using SPOT VGT data starting from 1999 has been introduced. The previous in situ validations ( D’Odorico et al. 2015; Gonsamo et al. 2013a; Gonsamo et al. 2012a; Gonsamo et al. 2012b) and the spatial distribution assessments of the current work show promising results. Additional validation presented in the current study also proves that the circumpolar vegetation dynamics product is an improvement over the operational global MODIS Combined Land Cover Dynamics (MCD12Q2) product. Given that the circumpolar vegetation dynamics product is intrinsically designed to suit a limited geographic region, its improved performance compared to the global MCD12Q2 product is expected. Both phenology and plant productivity (i.e., NDVI) dynamics show realistic spatial distributions that are geographically and ecologically consistent with the known behavior of land cover types and vegetation in this region. Several global change study applications have been presented in this work. All of the circumpolar vegetation dynamics product layers respond in the expected direction to the sea ice and leading teleconnection indices variabilities. Most importantly, the availability of the circumpolar vegetation dynamics product specifically designed for circumpolar north will allow monitoring changes in plant growth, phenology, photosynthetic capacity, north ward expansions, and associated feedbacks under climate change. The circumpolar vegetation dynamics product will be updated annually using the PROBA-V and Sentinel-3A sensors observations, which are the succession instruments for SPOT VGT.

All of the circumpolar vegetation dynamics product data files can freely be obtained by email to the authors or at https://goo.gl/eRKfbY. 


\section{Acknowledgments}

We thank the National Snow and Ice Data Center, NASA Goddard Space Flight Center, VITO SPOT VEGETATION programme, PlantWatch Canada regional networks and coordinators, Pan European Phenology Project, MODIS land cover dynamics processing team, and NOAA National Weather Service for making their data available. We are grateful to the FLUXNET network, the site principal investigators, co-investigators, data collection and processing staff, and the agencies and institutions that funded long-term measurements at these sites. The Bonanza Creek LTER, a partnership between the University of Alaska Fairbanks and the U.S. Forest Service acknowledges funding from the National

Science Foundation Long-Term Ecological Research program (NSF Grant numbers DEB0620579, DEB-0423442, DEB-0080609, DEB-9810217, DEB-9211769, DEB-8702629) and by the USDA Forest Service, Pacific Northwest Research Station (Agreement \# RJVA-PNW-01-JV-11261952231). Four anonymous reviewers provided valuable comments which greatly improved the manuscript.

\section{References}

Aasa, A., Jaagus, J., Ahas, R., \& Sepp, M. (2004). The influence of atmospheric circulation on plant phenological phases in central and eastern Europe. International Journal of Climatology, 24, 15511564

Ahrends, H.E., Brügger, R., Stöckli, R., Schenk, J., Michna, P., Jeanneret, F., Wanner, H., \& Eugster, W. (2008). Quantitative phenological observations of a mixed beech forest in northern Switzerland with digital photography. Journal of Geophysical Research: Biogeosciences, 113, G04004

Anderson, J., Elsner, C., Fathauer, T., \& Euskirchen, E.S. (2014). Greenup values for interior alaska 1976 - Present, Bonanza Creek LTER - University of Alaska Fairbanks. BNZ:300: http://www.lter.uaf.edu/data_detail.cfm?datafile_pkey=300. 
Arora, V.K., \& Boer, G.J. (2005). A parameterization of leaf phenology for the terrestrial ecosystem component of climate models. Global Change Biology, 11, 39-59.

Atkinson, P.M., Jeganathan, C., Dash, J., \& Atzberger, C. (2012). Inter-comparison of four models for smoothing satellite sensor time-series data to estimate vegetation phenology. Remote Sensing of Environment, 123, 400-417

Aubinet, M., Chermanne, B., Vandenhaute, M., Longdoz, B., Yernaux, M., \& Laitat, E. (2001). Long term carbon dioxide exchange above a mixed forest in the Belgian Ardennes. Agricultural and Forest Meteorology, 108, 293-315

Balzarolo, M., Vicca, S., Nguy-Robertson, A.L., Bonal, D., Elbers, J.A., Fu, Y.H., Grünwald, T., Horemans, J.A., Papale, D., Peñuelas, J., \& Suyker, A. (2016). Matching the phenology of Net Ecosystem Exchange and vegetation indices estimated with MODIS and FLUXNET in-situ observations. Remote Sensing of Environment, 174, 290-300.

Barichivich, J., Briffa, K., Myneni, R., Schrier, G., Dorigo, W., Tucker, C., Osborn, T., \& Melvin, T. (2014). Temperature and Snow-Mediated Moisture Controls of Summer Photosynthetic Activity in Northern Terrestrial Ecosystems between 1982 and 2011. Remote Sensing, 6, 1390

Barnston, A.G., \& Livezey, R.E. (1987). Classification, seasonality and persistence of low-frequency atmospheric circulation patterns. Monthly weather review, 115, 1083-1126

Beaubien, E.G., \& Hamann, A. (2011). Plant phenology networks of citizen scientists: recommendations from two decades of experience in Canada. International Journal of Biometeorology, 55, 833-841

Bergeron, O., Margolis, H. A., Black, T. A., Coursolle, C., Dunn, A. L., Barr, A. G., \& Wofsy, S. C. (2007). Comparison of carbon dioxide fluxes over three boreal black spruce forests in Canada. Global Change Biology, 13(1), 89-107 
Bhatt, U.S., Walker, D.A., Raynolds, M.K., Bieniek, P.A., Epstein, H.E., Comiso, J.C., Pinzon, J.E., Tucker, C.J., \& Polyakov, I.V. (2013). Recent Declines in Warming and Vegetation Greening Trends over Pan-Arctic Tundra. Remote Sensing, 5, 4229-4254

Bhatt, U.S., Walker, D.A., Raynolds, M.K., Comiso, J.C., Epstein, H.E., Jia, G., Gens, R., Pinzon, J.E., Tucker, C.J., Tweedie, C.E., \& Webber, P.J. (2010). Circumpolar Arctic Tundra Vegetation Change Is Linked to Sea Ice Decline. Earth Interactions, 14, 1-20

Black, T.A., den Hartog, G., Neumann, H.H., Blanken, P.D., Yang, P.C., Russell, C., Nesic, Z., Lee, X., Chen, S.G., Staebler, R., \& Novak, M.D. (1996). Annual cycles of water vapour and carbon dioxide fluxes in and above a boreal aspen forest. Global Change Biology, 2, 101-111

Boles, S.H., Xiao, X.M., Liu, J.Y., Zhang, Q.Y., Munkhtuya, S., Chen, S.Q., \& Ojima, D. (2004). Land cover characterization of Temperate East Asia using multi-temporal VEGETATION sensor data. Remote Sensing of Environment, 90, 477-489

Bonan, G.B. (2008). Forests and climate change: Forcings, feedbacks, and the climate benefits of forests. Science, 320, 1444-1449

Both, C., Bouwhuis, S., Lessells, C.M., \& Visser, M.E. (2006). Climate change and population declines in a long-distance migratory bird. Nature, 441, 81-83

Buitenwerf, R., Rose, L., \& Higgins, S.I. (2015). Three decades of multi-dimensional change in global leaf phenology. Nature Climate Change, 5, 364-368

Chen, B., Black, T.A., Coops, N.C., Hilker, T. Trofymow, J.A., \& Morgenstern, K. (2009). Assessing tower flux footprint climatology and scaling between remotely sensed and eddy covariance measurements. Boundary Layer Meteorology, 130,137-167.

Chmielewski, F.-M., \& Rotzer, T. (2002). Annual and spatial variability of the beginning of growing season in Europe in relation to air temperature changes. Climate research, 19, 257-264 
Claud, C., Duchiron, B., \& Terray, P. (2007). Associations between large-scale atmospheric circulation and polar low developments over the North Atlantic during winter. Journal of Geophysical Research: Atmospheres, 112, D12101

Cook, B.D., Davis, K.J., Wang, W., Desai, A., Berger, B.W., Teclaw, R.M., \& Heilman, W. (2004). Carbon exchange and venting anomalies in an upland deciduous forest in northern Wisconsin, USA. Agricultural and Forest Meteorology, 126, 271-295

Dash, J., \& Curran, P.J. (2004). The MERIS terrestrial chlorophyll index. International Journal of Remote Sensing, 25, 5403-5413

de Beurs, K.M., \& Henebry, G.M. (2004). Land surface phenology, climatic variation, and institutional change: Analyzing agricultural land cover change in Kazakhstan. Remote Sensing of Environment, $89,497-509$

de Beurs, K.M., \& Henebry, G.M. (2008). Northern annular mode effects on the land surface phenologies of northern Eurasia. Journal of Climate, 21, 4257-4279

DeFries, R. S., \& Townshend, J. R. G. (1994). NDVI-derived land cover classifications at a global scale. International Journal of Remote Sensing, 15, 3567-3586.

Delbart, N., Kergoat, L., Le Toan, T., Lhermitte, J., \& Picard, G. (2005). Determination of phenological dates in boreal regions using normalized difference water index. Remote Sensing of Environment, 97, 26-38

Delbart, N., Le Toan, T., Kergoat, L., \& Fedotova, V. (2006). Remote sensing of spring phenology in boreal regions: A free of snow-effect method using NOAA-AVHRR and SPOT-VGT data (19822004). Remote Sensing of Environment, 101, 52-62 
Delbart, N., Picard, G., Le Toans, T., Kergoat, L., Quegan, S., Woodward, I., Dye, D., \& Fedotova, V. (2008). Spring phenology in boreal Eurasia over a nearly century time scale. Global Change Biology, 14, 603-614

Dickinson, J.L., Zuckerberg, B., \& Bonter, D.N. (2010). Citizen Science as an Ecological Research Tool: Challenges and Benefits. Annual Review of Ecology, Evolution, and Systematics, 41, 149-172

D’Odorico, P., Gonsamo, A., Gough, C.M., Bohrer, G., Morison, J., Wilkinson, M., Hanson, P.J., Gianelle, D., Fuentes, J.D., \& Buchmann, N. (2015). The match and mismatch between photosynthesis and land surface phenology of deciduous forests. Agricultural and Forest Meteorology, 214-215, 25-38

Dunn, A. L., Barford, C. C., Wofsy, S. C., Goulden, M. L., \& Daube, B. C. (2007). A long-term record of carbon exchange in a boreal black spruce forest: Means, responses to interannual variability, and decadal trends. Global Change Biology, 13, 577-590

Edwards, M., \& Richardson, A.J. (2004). Impact of climate change on marine pelagic phenology and trophic mismatch. Nature, $430,881-884$

Fensholt, R., \& Proud, S.R. (2012). Evaluation of Earth Observation based global long term vegetation trends - Comparing GIMMS and MODIS global NDVI time series. Remote Sensing of Environment, $119,131-147$

Fensholt, R., Rasmussen, K., Nielsen, T.T., \& Mbow, C. (2009). Evaluation of earth observation based long term vegetation trends - Intercomparing NDVI time series trend analysis consistency of Sahel from AVHRR GIMMS, Terra MODIS and SPOT VGT data. Remote Sensing of Environment, 113, 1886-1898

Fetterer, F., Knowles, K., Meier, W., \& Savoie, M. (2009). Sea Ice Index of northern hemisphere. Boulder, Colorado USA: National Snow and Ice Data Center 
Garonna, I., De Jong, R., De Wit, A.J.W., Mucher, C.A., Schmid, B., \& Schaepman, M.E. (2014). Strong contribution of autumn phenology to changes in satellite-derived growing season length estimates across Europe (1982-2011). Global Change Biology, 20, 3457-3470

Gonsamo, A., \& Chen, J.M. (2015). Winter teleconnections can predict the ensuing summer European crop productivity. Proceedings of the National Academy of Sciences, 112, E2265-E2266.

Gonsamo, A., Chen, J. M., \& Lombardozzi, D. (2016a), Global vegetation productivity response to climatic oscillations during the satellite era. Global Change Biology, doi:10.1111/gcb.13258

Gonsamo, A., Chen, J.M., \& D'Odorico, P. (2013a). Deriving land surface phenology indicators from CO2 eddy covariance measurements. Ecological Indicators, 29, 203-207

Gonsamo, A., Chen, J.M., \& D'Odorico, P. (2015). Underestimated role of East Atlantic-West Russia pattern on Amazon vegetation productivity. Proceedings of the National Academy of Sciences of the United States of America, 112, E1054-E1055

Gonsamo, A., Chen, J.M., Price, D.T., Kurz, W.A., Liu, J., Boisvenue, C., Hember, R.A., Wu, C., \& Chang, K.-H. (2013b). Improved assessment of gross and net primary productivity of Canada's landmass. Journal of Geophysical Research-Biogeosciences, 118, 1546-1560

Gonsamo, A., Chen, J.M., Price, D.T., Kurz, W.A., \& Wu, C. (2012a). Land surface phenology from optical satellite measurement and $\mathrm{CO} 2$ eddy covariance technique. Journal of Geophysical Research-Biogeosciences, 117, G03032

Gonsamo, A., Chen, J.M., Shindell, D.T., \& Asner, G.P. (2016b). Coherence among the Northern Hemisphere land, cryosphere, and ocean responses to natural variability and anthropogenic forcing during the satellite era. Earth System Dynamics Discussion, doi:10.5194/esd-2015-92

Gonsamo, A., Chen, J.M., \& Wu, C. (2013c). Citizen Science: linking the recent rapid advances of plant flowering in Canada with climate variability. Scientific Reports, 3, 2239 
Gonsamo, A., Chen, J.M., Wu, C., \& Dragoni, D. (2012b). Predicting deciduous forest carbon uptake phenology by upscaling FLUXNET measurements using remote sensing data. Agricultural and Forest Meteorology, 165, 127-135

Gonsamo, A., \& D'Odorico, P. (2014). Citizen science: best practices to remove observer bias in trend analysis. International Journal of Biometeorology, 58, 2159-2163

Gough, C.M., Hardiman, B.S., Nave, L., Bohrer, G., Maurer, K.D., Vogel, C.S., Nadelhoffer, K.J., \& Curtis, P.S. (2013). Sustained carbon uptake and storage following moderate disturbance in a Great Lakes forest. Ecological Applications, 23, 1205-1215

Granier, A., Ceschia, E., Damesin, C., Dufrêne, E., Epron, D., Gross, P., \& Saugier, B. (2000). The carbon balance of a young beech forest. Functional Ecology, 14, 312-325

Hansen, M.C., Defries, R.S., Townshend, J.R.G., \& Sohlberg, R. (2000). Global land cover classification at $1 \mathrm{~km}$ spatial resolution using a classification tree approach. International Journal of Remote Sensing, 21, 1331-1364

Hinzman, L.D., Bettez, N.D., Bolton, W.R., Chapin, F.S., Dyurgerov, M.B., Fastie, C.L., Griffith, B., Hollister, R.D., Hope, A., Huntington, H.P., Jensen, A.M., Jia, G.J., Jorgenson, T., Kane, D.L., Klein, D.R., Kofinas, G., Lynch, A.H., Lloyd, A.H., McGuire, A.D., Nelson, F.E., Oechel, W.C., Osterkamp, T.E., Racine, C.H., Romanovsky, V.E., Stone, R.S., Stow, D.A., Sturm, M., Tweedie, C.E., Vourlitis, G.L., Walker, M.D., Walker, D.A., Webber, P.J., Welker, J.M., Winker, K., \& Yoshikawa, K. (2005). Evidence and implications of recent climate change in northern Alaska and other arctic regions. Climatic Change, 72, 251-298

Holben, B.N. (1986). Characteristics of maximum-value composite images from temporal avhrr data. International Journal of Remote Sensing, 7, 1417-1434 
Iizumi, T., Luo, J.-J., Challinor, A.J., Sakurai, G., Yokozawa, M., Sakuma, H., Brown, M.E., \& Yamagata, T. (2014). Impacts of El Niño Southern Oscillation on the global yields of major crops. Nature Communication, 5, 3712

Jackson, R.D., \& Huete, A.R. (1991). Interpreting vegetation indexes. Preventive Veterinary Medicine, $11,185-200$

Jeganathan, C., Dash, J., \& Atkinson, P.M. (2014). Remotely sensed trends in the phenology of northern high latitude terrestrial vegetation, controlling for land cover change and vegetation type. Remote Sensing of Environment, 143, 154-170

Jiang, Y., \& Zhuang, Q. (2011). Extreme value analysis of wildfires in Canadian boreal forest ecosystems. Canadian Journal of Forest Research, 41, 1836-1851

Jin, H., \& Eklundh, L. (2014). A physically based vegetation index for improved monitoring of plant phenology. Remote Sensing of Environment, 152, 512-525

Justice, C.O., Townshend, J.R.G., Holben, B.N., \& Tucker, C.J. (1985). Analysis of the phenology of global vegetation using meteorological satellite data. International Journal of Remote Sensing, 6, $1271-1318$

Knohl, A., Schulze, E.D., Kolle, O., \& Buchmann, N. (2003). Large carbon uptake by an unmanaged 250-year-old deciduous forest in Central Germany. Agricultural and Forest Meteorology, 118, 151167

Kurz, W.A., Dymond, C.C., Stinson, G., Rampley, G.J., Neilson, E.T., Carroll, A.L., Ebata, T., \& Safranyik, L. (2008). Mountain pine beetle and forest carbon feedback to climate change. Nature, $452,987-990$ 
Lafleur, P.M., Roulet, N.T., Bubier, J.L., Frolking, S., \& Moore, T.R. ( 2003). Interannual variability in the peatland-atmosphere carbon dioxide exchange at an ombrotrophic bog. Global Biogeochemical Cycles, 17, 1036

Le Maire, G., Davi, H., Soudani, K., Franc, ois, C., Le Dantec, V., \& Dufrêne, E. (2005). Modeling annual production and carbon fluxes of a large managed temperate forest using forest inventories, satellite data and field measurements. Tree Physiology, 25, 859-872

Liang, L., Schwartz, M. D., \& Fei, S. (2011). Validating satellite phenology through intensive ground observation and landscape scaling in a mixed seasonal forest. Remote Sensing of Environment, 115, $143-157$.

Liu, Y., Wu, C., Peng, D., Xu, S., Gonsamo, A., Jassal, R.S., Arain, M.A., Lu, L., Fang, B. \& Chen, J.M. (2016). Improved modeling of land surface phenology using MODIS land surface reflectance and temperature at evergreen needleleaf forests of central North America. Remote Sensing of Environment, 176, 152-162.

Macias-Fauria, M., Forbes, B.C., Zetterberg, P., \& Kumpula, T. (2012). Eurasian Arctic greening reveals teleconnections and the potential for structurally novel ecosystems. Nature climate change, $2,613-618$

Maisongrande, P., Duchemin, B., \& Dedieu, G. (2004). VEGETATION/SPOT: an operational mission for the Earth monitoring; presentation of new standard products. International Journal of Remote Sensing, 25, 9-14

Migliavacca, M., Sonnentag, O., Keenan, T.F., Cescatti, A., O'Keefe, J., \& Richardson, A.D. (2012). On the uncertainty of phenological responses to climate change, and implications for a terrestrial biosphere model. Biogeosciences, 9, 2063-2083 
Miller, I.R.a.E.S.a.J.R. (2013). Amplified warming projections for high altitude regions of the northern hemisphere mid-latitudes from CMIP5 models. Environmental Research Letters, 8, 024040

Moffat, A.M., Papale, D., Reichstein, M., Hollinger, D.Y., Richardson, A.D., Barr, A.G., Beckstein, C., Braswell, B.H., Churkina, G., Desai, A.R., Falge, E., Gove, J.H., Heimann, M., Hui, D., Jarvis, A.J., Kattge, J., Noormets, A., \& Stauch, V.J. (2007). Comprehensive comparison of gap-filling techniques for eddy covariance net carbon fluxes. Agricultural and Forest Meteorology, 147, 209232.

Nemani, R.R., Keeling, C.D., Hashimoto, H., Jolly, W.M., Piper, S.C., Tucker, C.J., Myneni, R.B., \& Running, S.W. (2003). Climate-driven increases in global terrestrial net primary production from 1982 to 1999. Science, $300,1560-1563$

Papale, D., Reichstein, M., Aubinet, M., Canfora, E., Bernhofer, C., Kutsch, W., Longdoz, B., Rambal, S., Valentini, R., Vesala, T., \& Yakir, D. (2006). Towards a standardized processing of Net Ecosystem Exchange measured with eddy covariance technique: algorithms and uncertainty estimation. Biogeosciences, 3, 571-583.

Parmentier, F.-J.W., Christensen, T.R., Sorensen, L.L., Rysgaard, S., McGuire, A.D., Miller, P.A., \& Walker, D.A. (2013). The impact of lower sea-ice extent on Arctic greenhouse-gas exchange. Nature Climate Change, 3, 195-202

Parmesan, C., \& Yohe, G. (2003). A globally coherent fingerprint of climate change impacts across natural systems. Nature, 421, 37-42

PEP725 (2015). PEP725 Pan European Phenology Data. http://www.pep725.eu

Pilegaard, K., Ibrom, A., Courtney, M.S., Hummelshøj, P., \& Jensen, N.O. (2011). Increasing net CO2 uptake by a Danish beech forest during the period from 1996 to 2009. Agricultural and Forest Meteorology, 151, 934-946 
Poloczanska, E.S., Brown, C.J., Sydeman, W.J., Kiessling, W., Schoeman, D.S., Moore, P.J., Brander, K., Bruno, J.F., Buckley, L.B., Burrows, M.T., Duarte, C.M., Halpern, B.S., Holding, J., Kappel, C.V., O'Connor, M.I., Pandolfi, J.M., Parmesan, C., Schwing, F., Thompson, S.A., \& Richardson, A.J. (2013). Global imprint of climate change on marine life. Nature Climate Change, 3, 919-925

Polyakov, I.V., Alekseev, G.V., Bekryaev, R.V., Bhatt, U., Colony, R.L., Johnson, M.A., Karklin, V.P., Makshtas, A.P., Walsh, D., \& Yulin, A.V. (2002). Observationally based assessment of polar amplification of global warming. Geophysical research letters, 29, 25-21-25-24

Post, E., Bhatt, U.S., Bitz, C.M., Brodie, J.F., Fulton, T.L., Hebblewhite, M., Kerby, J., Kutz, S.J., Stirling, I., \& Walker, D.A. (2013). Ecological Consequences of Sea-Ice Decline. Science, 341, 519524

Post, E., Forchhammer, M.C., Bret-Harte, M.S., Callaghan, T.V., Christensen, T.R., Elberling, B., Fox, A.D., Gilg, O., Hik, D.S., Hoye, T.T., Ims, R.A., Jeppesen, E., Klein, D.R., Madsen, J., McGuire, A.D., Rysgaard, S., Schindler, D.E., Stirling, I., Tamstorf, M.P., Tyler, N.J.C., van der Wal, R., Welker, J., Wookey, P.A., Schmidt, N.M., \& Aastrup, P. (2009). Ecological Dynamics Across the Arctic Associated with Recent Climate Change. Science, 325, 1355-1358

Quadrelli, R., \& Wallace, J.M. (2004). A simplified linear framework for interpreting patterns of Northern Hemisphere wintertime climate variability. Journal of Climate, 17, 3728-3744

Reichstein, M., Falge, E., Baldocchi, D., Papale, D., Aubinet, M., Berbigier, P., Bernhofer, C., Buchmann, N., Gilmanov, T., Granier, A., Grünwald, T., Havrankova, K., Ilvesniemi, H., Janous, D., Knohl, A., Laurila, T., Lohila, A., Loustau, D., Matteucci, G., Meyers, T., Miglietta, F., Ourcival, J.M., Pumpanen, J., Rambal, S., Rotenberg, E., Sanz, M., Tenhunen, J., Seufert, G., Vaccari, F., Vesala, T., Yakir, D., \& Valentini, R. (2005). On the separation of net ecosystem 
exchange into assimilation and ecosystem respiration: review and improved algorithm. Global Change Biology, 11, 1424-1439.

Richardson, A.D., Braswell, B.H., Hollinger, D.Y., Jenkins, J.P., \& Ollinger, S.V. (2009). Near-surface remote sensing of spatial and temporal variation in canopy phenology. Ecological Applications, 19, $1417-1428$

Richardson, A.D., Jenkins, J.P., Braswell, B.H., Hollinger, D.Y., Ollinger, S.V., \& Smith, M.-L. (2007). Use of digital webcam images to track spring green-up in a deciduous broadleaf forest. Oecologia, $152,323-334$

Rodriguez-Galiano, V.F., Dash, J., \& Atkinson, P.M. (2015). Intercomparison of satellite sensor land surface phenology and ground phenology in Europe. Geophyscal Research Letter, 42

Schwartz, M.D., \& Hanes, J.M. (2010). Intercomparing multiple measures of the onset of spring in eastern North America. International Journal of Climatology, 30, 1614-1626

Serreze, M.C., Walsh, J.E., Chapin, F.S., Osterkamp, T., Dyurgerov, M., Romanovsky, V., Oechel, W.C., Morison, J., Zhang, T., \& Barry, R.G. (2000). Observational evidence of recent change in the northern high-latitude environment. Climatic Change, 46, 159-207

Shabanov, N.V., Zhou, L.M., Knyazikhin, Y., Myneni, R.B., \& Tucker, C.J. (2002). Analysis of interannual changes in northern vegetation activity observed in AVHRR data from 1981 to 1994. Ieee Transactions on Geoscience and Remote Sensing, 40, 115-130

Stroeve, J.C., Serreze, M.C., Holland, M.M., Kay, J.E., Malanik, J., \& Barrett, A.P. (2012). The Arctic's rapidly shrinking sea ice cover: a research synthesis. Climatic Change, 110, 1005-1027

Sulman, B., Desai, A., Cook, B.D., Saliendra, N., \& Mackay, D.S. (2009). Contrasting carbon dioxide fluxes between a drying shrub wetland in northern Wisconsin, USA, and nearby forests. Biogeosciences, 6, 1115-1126. 
Todd, S.W., \& Hoffer, R.M. (1998). Responses of spectral indices to variations in vegetation cover and soil background. Photogrammetric Engineering and Remote Sensing, 64, 915-921

Tucker, C.J., Slayback, D.A., Pinzon, J.E., Los, S.O., Myneni, R.B., \& Taylor, M.G. (2001). Higher northern latitude normalized difference vegetation index and growing season trends from 1982 to 1999. International Journal of Biometeorology, 45, 184-190

Venegas, S.A., \& Mysak, L.A. (2000). Is there a dominant timescale of natural climate variability in the Arctic? Journal of Climate, 13, 3412-3434

Wallace, J.M., \& Gutzler, D.S. (1981). Teleconnections in the geopotential height field during the Northern Hemisphere winter. Monthly Weather Review, 109, 784-812

Walther, G.R. (2010). Community and ecosystem responses to recent climate change. Philosophical Transactions of the Royal Society B: Biological Sciences, 365, 2019-2024

Walther, G.R., Post, E., Convey, P., Menzel, A., Parmesan, C., Beebee, T.J.C., Fromentin, J.M., HoeghGuldberg, O., \& Bairlein, F. (2002). Ecological responses to recent climate change. Nature, 416, 389-395

White, M.A., de Beurs, K.M., Didan, K., Inouye, D.W., Richardson, A.D., Jensen, O.P., O'Keefe, J., Zhang, G., Nemani, R.R., van Leeuwen, W.J.D., Brown, J.F., de Wit, A., Schaepman, M., Lin, X., Dettinger, M., Bailey, A.S., Kimball, J., Schwartz, M.D., Baldocchi, D.D., Lee, J.T., \& Lauenroth, W.K. (2009). Intercomparison, interpretation, and assessment of spring phenology in North America estimated from remote sensing for 1982-2006. Global Change Biology, 15, 2335-2359

Wibig, J. (1999). Precipitation in Europe in relation to circulation patterns at the $500 \mathrm{hPa}$ level. International Journal of Climatology, 19, 253-269 
Wilkinson, M., Eaton, E.L., Broadmeadow, M.S.J., \& Morison, J.I.L. (2012). Inter-annual variation of carbon uptake by a plantation oak woodland in south-eastern England. Biogeoscience Discussion, 9, 9667-9710

Wolkovich, E.M., Cook, B.I., Allen, J.M., Crimmins, T.M., Betancourt, J.L., Travers, S.E., Pau, S., Regetz, J., Davies, T.J., Kraft, N.J.B., Ault, T.R., Bolmgren, K., Mazer, S.J., McCabe, G.J., McGill, B.J., Parmesan, C., Salamin, N., Schwartz, M.D., \& Cleland, E.E. (2012). Warming experiments underpredict plant phenological responses to climate change. Nature, 485, 494-497

Woodward, F., Lomas, M., \& Quaife, T. (2008). Global responses of terrestrial productivity to contemporary climatic oscillations. Philosophical Transactions of the Royal Society B: Biological Sciences, 363, 2779-2785

Wu, C., Hou, X., Peng, D., Gonsamo, A., \& Xu, S. (2016). Land surface phenology of China's temperate ecosystems over 1999-2013: Spatial-temporal patterns, interaction effects, covariation with climate and implications for productivity. Agricultural and Forest Meteorology, 216, 177-187.

Xu, L., Myneni, R.B., Chapin, F.S., III, Callaghan, T.V., Pinzon, J.E., Tucker, C.J., Zhu, Z., Bi, J., Ciais, P., Tommervik, H., Euskirchen, E.S., Forbes, B.C., Piao, S.L., Anderson, B.T., Ganguly, S., Nemani, R.R., Goetz, S.J., Beck, P.S.A., Bunn, A.G., Cao, C., \& Stroeve, J.C. (2013). Temperature and vegetation seasonality diminishment over northern lands. Nature Climate Change, 3, 581-586

Yan, E., Wang, G., Lin, H., Xia, C., \& Sun, H. (2015). Phenology-based classification of vegetation cover types in Northeast China using MODIS NDVI and EVI time series. International Journal of Remote Sensing, 36, 489-512.

Zeng, H., Jia, G., \& Epstein, H. (2011). Recent changes in phenology over the northern high latitudes detected from multi-satellite data. Environmental Research Letters, 6, 4 
Zhang, X.Y., Friedl, M.A., Schaaf, C.B., \& Strahler, A.H. (2004). Climate controls on vegetation phenological patterns in northern mid- and high latitudes inferred from MODIS data. Global Change Biology, 10, 1133-1145

Zhang, X.Y., Friedl, M.A., Schaaf, C.B., Strahler, A.H., Hodges, J.C.F., Gao, F., Reed, B.C., \& Huete, A. (2003). Monitoring vegetation phenology using MODIS. Remote Sensing of Environment, 84, $471-475$

\section{LIST OF FIGURE CAPTIONS}

Fig. 1. Example time evolution of normalized difference vegetation index (NDVI), normalized difference infrared index (NDII) and phenology index (PI) averaged over the entire circumpolar north for the year 2013 for five biomes based on the University of Maryland Global Land Cover Classification scheme (Hansen et al. 2000). The error bars indicate 1 standard deviation of the spatial averaging.

Fig. 2. Comparisons between satellite estimated LSP and ground phenology observations of Birch (Betula Pendula) which were obtained from Pan European Phenology network (PEP725) (PEP725 2015) for entire Finland for which both leaf unfolding and colouring dates are available for 1999-2005 $(\mathrm{n}=110)$. Each satellite $4 \times 4 \mathrm{~km}$ pixel is compared with a single ground observation record.

Fig. 3. Comparisons between circumpolar vegetation dynamics product, and ground phenology and meteorology observations. From Canada Citizen Science networks phenology records: a) SOS day of year (DOY) relationship with Larch leafing out $(\mathrm{n}=9, R=0.13, p=0.739)$, Bearberry first bloom day ( $\mathrm{n}=$ $10, R=0.51, p=0.136)$ and January-May growing degree day (GDD) $(R=-0.66, p=0.006)$; and $\mathrm{c})$ relationship between growing season integrated annual NDVI and annual GDD ( $R=0.57, p=0.026)$. From U.S.A LTER Bonanza Creek phenology records: b) SOS relationship with greenup DOY ( $n=15$, $R=0.49, p=0.063)$ and January-May GDD $(R=-0.58, p=0.024)$; and d) relationship between growing season integrated annual NDVI and annual GDD $(R=0.57, p=0.026)$. For all sites, the SOS and annual 
NDVI values are extracted over 20x20 km areas around phenology recording sites, and both the average and standard deviation (error bars) values are presented.

Fig. 4. Evaluation of PI-based circumpolar vegetation dynamics (CVD) and MODIS-based Land Cover Dynamics (MLCD, MCD12Q2) against land surface phenology estimates from in situ gross primary productivity (GPP) measurements. Site descriptions are given in Table 3. DBF = deciduous broadleaf forest, $\mathrm{ENF}=$ evergreen needleleaf forest, $\mathrm{MIX}=$ mixed forest, and $\mathrm{WL}=$ wetland. Both CVD and MLCD land surface phenology estimates are from $4 \times 4 \mathrm{~km}$ grid for each site.

Fig. 5. Spatial distributions of the mean SOS, EOS, LOS and the growing season integrated annual NDVI of the circumpolar north $\left(>45^{\circ} \mathrm{N}\right)$ during the period 1999-2013 at 4x4 km spatial resolution. All categories are mapped in 10 equal quantile classes, meaning each category of the legend contains $10 \%$ of the entire circumpolar north valid land pixels. The colour ramp for EOS is switched for visual clarity.

Fig. 6. Spatial distributions of the linear trends in SOS, EOS, LOS and the growing season integrated annual NDVI of the circumpolar north $\left(>45^{\circ} \mathrm{N}\right)$ during the period 1999-2013 at $4 \times 4 \mathrm{~km}$ spatial resolution. Linear trends are calculated using a Theil-Sen method for pixels which have successful retrievals for all 15 years. NS is not significant trend at $p=0.05$ (two tailed Student's t-test).

Fig. 7. Relationships among spatially averaged mean annual SOS, EOS, LOS and growing season integrated annual NDVI of the entire circumpolar north $\left(>45^{\circ} \mathrm{N}\right)$ during the period 1999-2013.

Fig. 8. Relationships among spring, summer and autumn sea ice extent and SOS, EOS, LOS and the growing season integrated annual NDVI of the circumpolar north $\left(>45^{\circ} \mathrm{N}\right)$ during the period 1999 2013 at $4 \times 4 \mathrm{~km}$ spatial resolution. All datasets are detrended. All colour shaded values are significant at 95\% confidence level from a two tailed Student's t-test.

Fig. 9. Impacts of the three leading circumpolar teleconnection patterns on SOS, EOS, LOS and the growing season integrated annual NDVI of the circumpolar north $\left(>45^{\circ} \mathrm{N}\right)$ during the period 1999 
2013 at 4x4 km spatial resolution. The Scandinavian Pattern (SCA), Polar/ Eurasia Pattern (POL) and North Atlantic Oscillation (NAO) teleconnection anomalies are calculated as a mean value of December of the preceding year and January, February and March of the LSP and NDVI year. All datasets are detrended. All colour shaded values are significant at 95\% confidence level from a two tailed Student's t-test.

Fig. 10. Long-term trend relationships between the mean anomalies of SOS, EOS, LOS and the growing season integrated annual NDVI of the circumpolar north $\left(>45^{\circ} \mathrm{N}\right)$, and the most explaining variables from Fig. 8 and 9 interannual variability relationships. AS SIE = August and September sea ice extent, $\mathrm{POL}=$ Polar/ Eurasia Pattern, and GS = growing season. Growing season sea ice extent (GS SIE) is calculated as average of April to September values. 
Graphical abstract

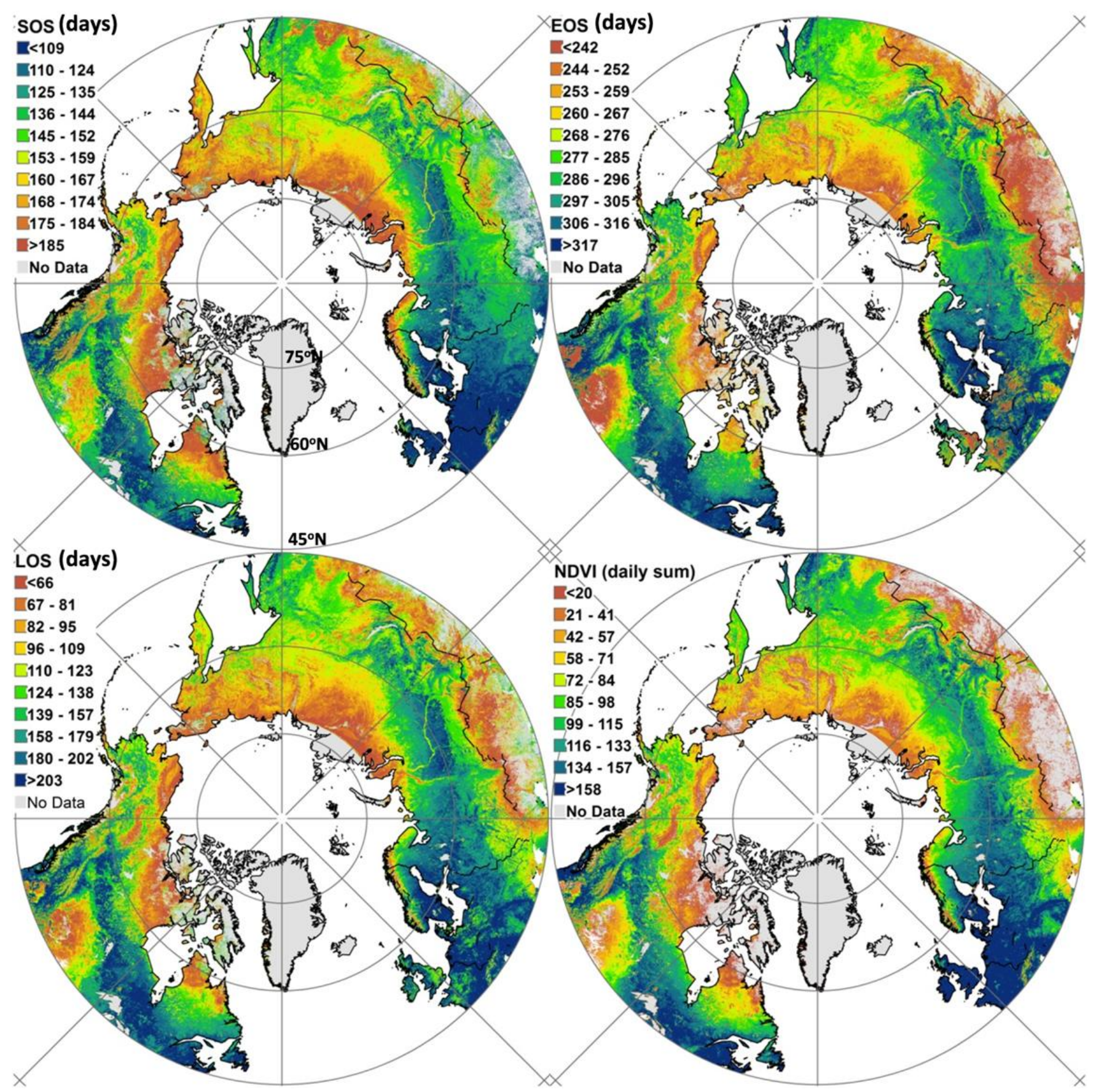

